Research Article

\title{
New Anticracking Glass-Fiber-Reinforced Cement Material and Integrated Composite Technology with Lightweight Concrete Panels
}

\author{
Dong Chen, ${ }^{1}$ Junjie Deng, ${ }^{1}$ Baoquan Cheng $\mathbb{C}^{2},{ }^{2}$ Qiong Wang, ${ }^{3}$ and Baojun Zhao ${ }^{3}$ \\ ${ }^{1}$ BIM Engineering Center of Anhui Province, Anhui Jianzhu University, Hefei, Anhui 230601, China \\ ${ }^{2}$ School of Civil Engineering, Central South University, Changsha, Hunan 410083, China \\ ${ }^{3}$ Shenzhen Hailong Construction Technology Company Limited, Shenzhen, Guangdong 518000, China
}

Correspondence should be addressed to Baoquan Cheng; curtis_ch@163.com

Received 6 May 2021; Revised 14 August 2021; Accepted 23 August 2021; Published 6 September 2021

Academic Editor: Kim Hung Mo

Copyright (c) 2021 Dong Chen et al. This is an open access article distributed under the Creative Commons Attribution License, which permits unrestricted use, distribution, and reproduction in any medium, provided the original work is properly cited.

Glass-fiber-reinforced cement (GRC) is a widely used decorative material for wall facades. Conventional GRC products have poor crack resistance, low construction efficiency, poor integration, and few environmental benefits, hence failing to meet the requirements of building industrialization. To realize an integrated composite wall made from GRC and precast lightweight concrete (PLC) with a lasting anticrack effect, the anticracking properties of GRC material as well as the connection mode of GRC and PLC layers were studied. Through long-term shrinkage test, the influence of fiber content, rubber powder content, and expansion agent content on the crack resistance of GRC material was systematically analyzed. At the same time, the influence of connection mode on the crack resistance of the GRC layer after compositing with precast lightweight concrete (PLC) was analyzed. The results showed that adding fiber can effectively improve the flexural strength of the GRC and reduce drying shrinkage, whereas adding rubber powder can effectively improve its toughness and crack resistance. The addition of U-type expansion agent (UEA) can impart the cement mortar with a certain degree of microexpansion performance and help improve the drying shrinkage of the GRC. Compared with other compounding methods, the smooth connection of the GRC and PLC can effectively reduce the shrinkage of the GRC surface layer and improve its crack resistance. So, the new GRC material has good crack resistance performance and facade effect. These research studies provide an experimental basis for the large-scale application of the panel, and it has great advantages in improving the efficiency of prefabricated building construction.

\section{Introduction}

Most external walls of modern buildings use external insulation and lacquer material. The exterior walls typically deteriorate in approximately five years, bringing security risks [1]. Glass-fiber-reinforced cement (GRC) is a type of composite material composed of a cement mortar as the base material and alkali-resistant glass fiber as an additional component. It is considered a green building material and has characteristics such as energy savings and environmental protection. At the same time, greenhouse gas emissions from building construction can be reduced [2]. Precast lightweight concrete (PLC) is a kind of precast lightweight aggregate concrete. It is made of light plastic particles, ordinary sand, cement, and water. The PLC strength grade in this paper was LC15 (i.e.15 MPa) [3]. A GRC-PLC-integrated composite panel (Figure 1) can effectively ensure wall insulation and reduce the generation of waste, waste gas, and wastewater in buildings. The type of fiber used has a significant influence on the plastic shrinkage and cracking of concrete. Experimental results have shown that glass fiber imparts better mechanical properties and economy when added to concrete products [4-7]. El-Dieb and Reda Taha [8] reported an improvement in the self-compacting performance of concrete when incorporated with glass fibers, thereby reducing cracks and increasing its strength. Li et al. [9] studied the effect of glass fibers of different dimensions on the flexural performance of GRC and experimentally 


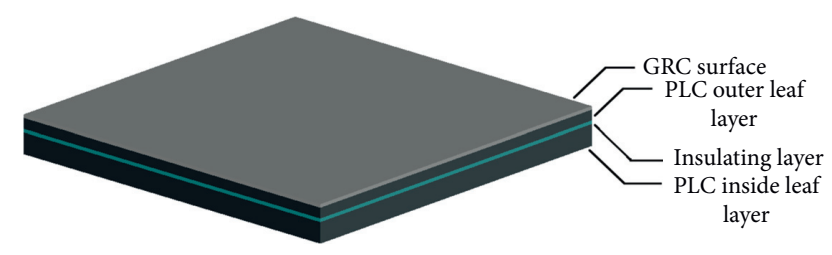

FIgURE 1: Three-dimensional model of a GRC-PLC-integrated panel.

showed that the higher the dimensions of the glass fiber, the better the strength and toughness of the GRC material. Because of the alkalinity of cementitious materials, the GRC becomes brittle, and the material strength is reduced. The use of additives can prevent GRC embrittlement [10-13]. The results of cracking and shrinkage experiments conducted on GRC materials and the analysis of fracture characteristics have shown that the addition of fly ash, rubber powder, expansion agent, and other materials can help effectively reduce the cracking and shrinkage of GRC [12-18]. Wu et al. [19] studied the shrinkage performance of GRC-based materials and showed that GRC materials made from different types of cement exhibit drying and autogenous shrinkage to varying degrees. When using GRC, the durability and strength of the material are important factors. By predicting the strength, durability, and aging degree of GRC materials, various strength and durability models have been proposed, assuming excessive loss of strength, to perform accelerated aging tests. The aging degree of GRC materials can be analyzed through nondestructive testing [20-23]. The cracking and deformation of GRC materials are significantly affected by the temperature. Correia et al. $[24,25]$ found that a GRC panel cracks and deforms excessively because of the thermal effect, GRC thickness, and dry humidity. Therefore, the effects of temperature and GRC thickness should be considered when monitoring the shrinkage strain of GRC panels.

In summary, current research on the physical and mechanical properties of GRC, such as the crack resistance, has mainly focused on a single GRC precast component, while studies on composite precast components made of GRC and PLC are lacking. But GRC and PLC are two different building materials, with different shrinkage properties. The shrinkage of PLC is smaller than that of GRC. After the composite, the PLC layer will hinder the shrinkage deformation of the GRC layer, thus tensile stress will be generated in the GRC layer. When the stress exceeds the tensile strength of the GRC, the GRC layer will produce cracks, which affects the overall facade effect of the decorative, integrated precast concrete component. So, it was studied from three aspects: reducing GRC material shrinkage, improving the tensile strength of GRC materials, and determining the most effective connection method for the GRC and PLC layers.

The research ideas of this paper are as follows. First of all, an anticrack GRC formula was developed. Considering the temperature and humidity, the effects of fiber content, rubber powder content, expansion agent content on the crack resistance of the GRC surface layer were systematically studied. And the flexural strength and dry shrinkage of the material were measured. Second, according to the different connection methods of GRC layer and PLC layer, seven panels of $1 \mathrm{~m} \times 1 \mathrm{~m}$ were prepared, and the shrinkage experiment was carried out for 365 days in environments with different temperature and humidity. Among them, the crack resistance of GRC layer was the core of the test. Finally, according to experimental results, the anticrack GRC formula and reasonable connection method between GRC layer and PLC layer were determined. Findings from this research contribute to the application of GRC-PLC composite panels and promotion of prefabrication.

\section{Materials and Methods}

\subsection{Materials}

2.1.1. Raw Materials. The main materials used in the experiment were GRC cement mortar and precast lightweight concrete. The GRC material was made on the experimental site, and raw materials of GRC were cement (for use as PW 52.5 grade white silicate cement); sand (for use as river sand, the fineness modulus is 1.4); water-reducing admixture (for use as PCA-1 polycarboxylate superplasticizer); fiber (shortcut alkali-resistant glass, the density is $2.68 \mathrm{~g} / \mathrm{cm}^{3}$, the elastic modulus is $72 \mathrm{GPa}$, the tensile strength is $1700 \mathrm{MPa}$, and the diameter is $14 \mu \mathrm{m}$ ); rubber powder (for use as redispersible emulsion powder), and U-type expansion agent (mainly composed of aluminum sulfate, aluminum oxide, aluminum potassium sulfate, and other expansive sources, which can improve the crack resistance of materials). PLC was used in the form of a ready-mix concrete provided by commercial concrete company. After the composite wall panel was poured, the surface of the wall panel was covered with plastic film for curing. The curing method was three times of watering in the morning, middle, and night, lasting three days, and the targeted strength of PLC was $15 \mathrm{MPa}$.

2.1.2. GRC Mix Proportion Design. In the preparation process of GRC materials, some experimental studies have shown that their fluidity and shrinkage are affected by the contents of glass fiber, rubber powder, and expansion agent [26-31]. Adding glass fiber can help reduce the generation and expansion of cracks; however, too high or too low a glass fiber content will produce different degrees of cracking in GRC materials [26-28]. Adding rubber powder into a GRC material can reduce internal voids, improve the hydrophilicity of cement, and improve the flexibility and fluidity of the GRC material. The addition of an expansion agent into concrete can help reduce the bonding cracks between the hydration products and aggregates and reduce the cracks due to drying shrinkage of materials [26, 29, 31].

The materials used in the new GRC anticrack formulation research include cement, sand, fly ash, metakaolin, water-reducing admixture, glass fiber, rubber powder, and expansion agent. The fly ash and metakaolin used can replace a part of the cement, reduce the amount of cement, decrease the hydration rate, and reduce the cracking and 
shrinkage of GRC materials. The emulsified rubber powder has the effect of bonding polymerization and improves the bonding strength between the cement, aggregate, and fiber. The crack resistance of a GRC material can be improved by adding glass fiber and U-type expansion agent. Table 1 lists the foundation mix proportion of the mortar. Table 2 lists the designed values of the fiber, rubber powder, and expansion agent. The contents of fly ash, metakaolin, waterreducing admixture, rubber powder, and expansion agent are a percentage of the total cementitious materials, whereas the fiber content is the percentage of the total mass of the sample. The content of fly ash and metakaolin was fixed at $10 \%$, and the water reducer is content was fixed at $2 \%$. In this study, the water-to-cement ratio of the mortar was designed as 0.28 . It is proposed to reduce shrinkage and improve the tensile strength of cement-based materials, and the effects of fiber, rubber powder, and expansion agent on the mechanical properties and crack resistance of GRC were systematically studied: (1) the effects of $1 \%, 1.5 \%$, and $2 \%$ fiber incorporation on the flexural strength and drying shrinkage properties of mortar were studied; (2) the effects of $1.5 \%$, $2.5 \%$, and $3.5 \%$ rubber powder on the flexural strength and drying shrinkage properties of the mortar were analyzed; and (3) on the basis of $1 \%$ fiber content, the effect of adding a certain amount of expansion agent on the drying shrinkage properties of the GRC was studied.

2.2. Experimental Equipment. In the experiment, concrete mixer was used to stir the GRC materials. The mixer has advantages of convenient operation, high mixing efficiency, and convenient cleaning. It is an ideal concrete mixing equipment for laboratory use. The flexural tester was used to measure the flexural strength of the specimen. The maximum test force was $1 \mathrm{kN}$ when the single lever was used, and the maximum test force was $5 \mathrm{kN}$ when the double lever was used. The accuracy was in the range of $0.4-1.0 \mathrm{~N}$. The comparator, depending on the requirements, can help determine the GRC specimens at each age of the shrinkage rate. The static strain tester was used to connect the surface strain gauge and embedded strain gauge to monitor the shrinkage strain of the composite panel over a long duration. Figure 2 shows the experimental equipment.

\subsection{Specimen Preparation}

2.3.1. Preparation of Specimen for Flexural Experiment. In the experiment, the fiber and cement were mixed for $3 \mathrm{~min}$, and it was put into concrete mixer (the capacity of the mixer was $60 \mathrm{~L}$, and the rotational speed of the stirring shaft was $45 \pm 2 \mathrm{r} /$ $\mathrm{min})$. Then water and sand were added, and the mixture was poured into a $40 \mathrm{~mm} \times 40 \mathrm{~mm} \times 160 \mathrm{~mm}$ mold after mixing. After molding, the specimens were cured in a standard environment for $24 \mathrm{~h}$ (temperature $20^{\circ} \mathrm{C} \pm 2^{\circ} \mathrm{C}$, relative humidity above $95 \% \mathrm{RH}$ ). When the standard curing specimen was removed from the mold, it was placed in an adjustable temperature and humidity box, and different relative humidity $(\mathrm{RH}=40 \%$ and $\mathrm{RH}=70 \%)$ values were set. Table 3 presents the number of specimens. The fiber contents were $1 \%, 1.5 \%$, and
$2 \%$. The rubber powder contents were $1.5 \%, 2.5 \%$, and $3.5 \%$. Under $\mathrm{RH}=40 \%$ and $\mathrm{RH}=70 \%$, specimens of different material contents were prepared, and three specimens of each content were made. The specimens were cured to the specified age, and the corresponding specimen was removed from the adjustable temperature and humidity box. The flexural experiment was carried out using a flexural testing machine. The flexural strength at different specified ages was tested in accordance with ISO 679:2009 [32]. Thus, the flexural strength of GRC materials was measured under different $\mathrm{RH}$ values.

\subsubsection{Preparation of Specimen for Drying Shrinkage} Experiment. The molding and curing processes employed for the drying shrinkage specimens were the same as those employed for the flexural specimens. A $25 \mathrm{~mm} \times 25 \mathrm{~mm}$ $\times 280 \mathrm{~mm}$ triple mold was used, and nail heads were placed at both ends of the triple mold to make dry shrinkage test specimens. After molding, the specimens were cured in a standard environment for $24 \mathrm{~h}$ (temperature $20^{\circ} \mathrm{C} \pm 2^{\circ} \mathrm{C}$, relative humidity above $95 \% \mathrm{RH}$ ). After removing the mold, the specimens were placed in the adjustable temperature and humidity box for curing, $20 \pm 2^{\circ} \mathrm{C}$, and different relative humidity ( $\mathrm{RH}=40 \%$ and $\mathrm{RH}=70 \%$ ) values were set. Curing to different ages, dry shrinkage experiment was carried out to prepare the specimens, as shown in Figure 3. Table 4 lists the number of specimens. The fiber contents were $1 \%, 1.5 \%$, and $2 \%$. The rubber powder contents were $0 \%, 1.5 \%, 2.5 \%$, and $3.5 \%$. UEA content was $8 \%$. Under $\mathrm{RH}=40 \%$ and $\mathrm{RH}=70 \%$, specimens of different material contents were prepared, and three specimens of each content were made. A comparator was used to measure the specimen length at different curing ages. So, the drying shrinkage of GRC materials was measured under different RH values. The calculation formula for the drying shrinkage rate of the cement mortar at different ages is as follows:

$$
P_{t}=\frac{L_{t}-L_{0}}{250} \times 100 \%,
$$

where $P_{t}$ is the drying shrinkage rate on day $\mathrm{t}(\mathrm{mm})$; the effective length of the mortar specimen is $250 \mathrm{~mm}$; $L_{t}$ is the measured length of the mortar specimen on day $\mathrm{t}(\mathrm{mm})$; and $L_{0}$ is the initial length of the mortar specimen $(\mathrm{mm})$.

\subsubsection{Specimens Prepared Using Different Connection} Methods. A total of seven composite panels were used in the experiment. Table 5 lists their dimensions and parameters, where T0 was a pure GRC panel without fiber, T1 was a pure lightweight concrete panel with a thickness of $60 \mathrm{~mm}$, and T2 was a pure GRC panel with a thickness of $15 \mathrm{~mm}$. These two types of panels were used as the basis for the experiment.

T3-T6 were GRC-PLC composite panels made according to Figure 1, which ignored the concrete structure layer and the insulation layer, as shown in Figure 4. The T3 and T4 panels have different GRC material thicknesses. It was used to study the effect of different GRC material thickness on the shrinkage performance of composite panel.

Based on the actual application of the composite panel, the common connection modes for composite panels include smooth connection, rough connection, and laying steel mesh 
TABLE 1: Mortar mix proportion.

\begin{tabular}{lcccccc}
\hline Type & Cement $\left(\mathrm{kg} / \mathrm{m}^{3}\right)$ & Sand $\left(\mathrm{kg} / \mathrm{m}^{3}\right)$ & Water $\left(\mathrm{kg} / \mathrm{m}^{3}\right)$ & Fly ash $\left(\mathrm{kg} / \mathrm{m}^{3}\right)$ & Metakaolin $\left(\mathrm{kg} / \mathrm{m}^{3}\right)$ & Water-reducing admixture $\left(\mathrm{kg} / \mathrm{m}^{3}\right)$ \\
\hline Content & 888 & 1248 & 322 & 56 & 166 & 31 \\
\hline
\end{tabular}

TABLE 2: Values of fiber, rubber powder, and expansion agent contents.

\begin{tabular}{lccc}
\hline Number & Fiber content (\%) & Rubber powder content (\%) & U-type expansion agent content (\%) \\
\hline 1 & 1 & 0 & 0 \\
2 & 1.5 & 0 & 0 \\
3 & 2 & 0 & 0 \\
4 & 2 & 1.5 & 0 \\
5 & 2 & 2.5 & 0 \\
6 & 2 & 3.5 & 0 \\
7 & 1 & 0 & 8 \\
\hline
\end{tabular}

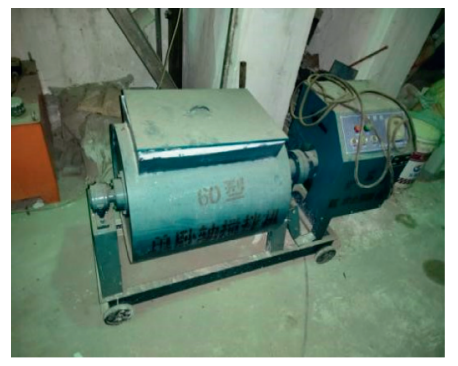

(a)

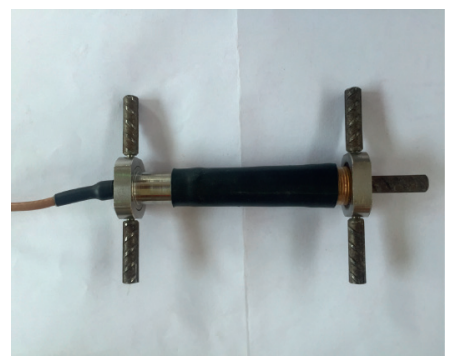

(d)

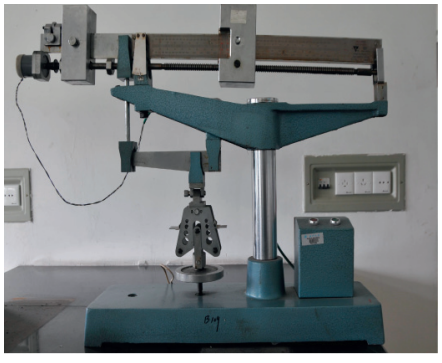

(b)

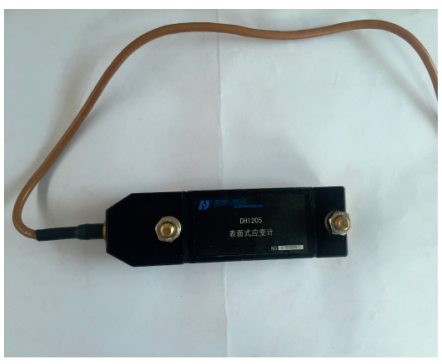

(e)

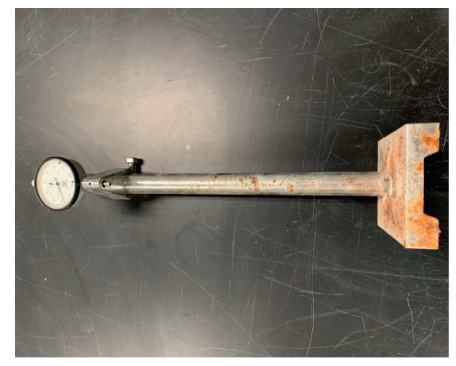

(c)

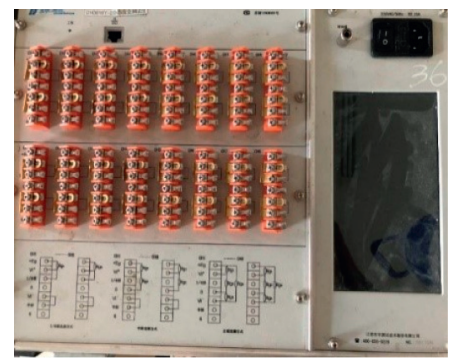

(f)

Figure 2: Experimental equipment. (a) Concrete mixer. (b) Flexural testing machine. (c) Comparator. (d) Embedded strain gauge. (e) Surface strain gauge. (f) Strain tester.

TABLe 3: Number of specimens.

\begin{tabular}{lccc}
\hline RH (\%) & Materials (content) & Number (pcs) & Remarks \\
\hline \multirow{2}{*}{40} & Fiber $(1 \%, 1.5 \%, 2 \%)$ & 9 & Three specimens were prepared for each content \\
& Rubber powder $(1.5 \%, 2.5 \%, 3.5 \%)$ & 9 & Three specimens were prepared for each content \\
\hline \multirow{2}{*}{70} & Fiber $(1 \%, 1.5 \%, 2 \%)$ & 9 & Three specimens were prepared for each content \\
& Rubber powder $(1.5 \%, 2.5 \%, 3.5 \%)$ & 9 & Three specimens were prepared for each content \\
\hline
\end{tabular}

connection. T4-T6 differed in terms of the connection method of the composite interface, with T4 having a smooth connection, T5 having a rough connection, and T6 having a steel mesh connection. The influence of the connection methods on the shrinkage performance of the composite panels was studied.

The design ideas of these panels were as follows: T0 was a panel without fiber, which was mainly used to observe the development trend of cracks, so as to determine the location of the strain gauge. T3-T6 took the GRC thickness and the connection methods as variables to determine the suitable structure type of GRC-PLC composite panel. The shrinkage experiment was carried out for 12 months to monitor the change of shrinkage strain in GRC and PLC with different temperature and humidity.

Before the experiment, the wood formwork was checked and cleaned. The ready-mix lightweight concrete was poured to a specified height while minimizing bubbles using hand-held vibrating rods. To weigh the required GRC anticracking 


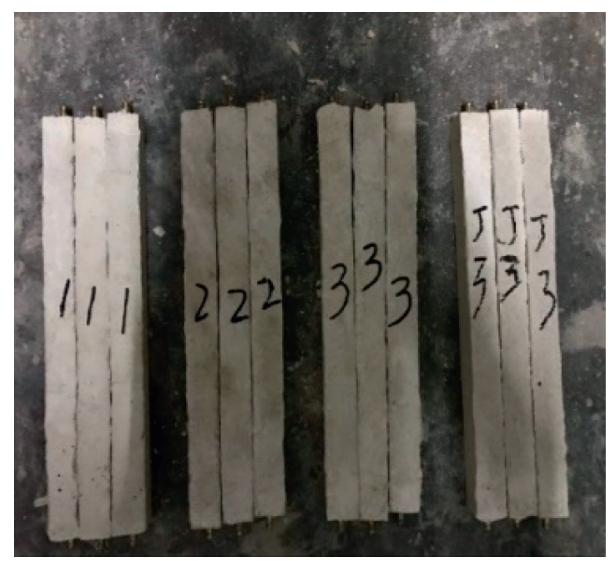

FIGURE 3: Preparation of drying shrinkage test specimen.

TABle 4: Number of specimens.

\begin{tabular}{lccc}
\hline RH (\%) & Materials (content) & Number & Remarks \\
\hline \multirow{2}{*}{40} & Fiber $(1 \%, 1.5 \%, 2 \%)$ & 9 & Three specimens were prepared for each content \\
& Rubber powder $(0 \%, 1.5 \%, 2.5 \%, 3.5 \%)$ & 12 & Three specimens were prepared for each content \\
\hline \multirow{2}{*}{70} & Fiber $(1 \%, 1.5 \%, 2 \%)$ & 3 & - \\
& Rubber powder $(0 \%, 1.5 \%, 2.5 \%, 3.5 \%)$ & 9 & Three specimens were prepared for each content \\
& & 12 & Three specimens were prepared for each content \\
\hline
\end{tabular}

Table 5: Parameters of a new GRC-PLC composite panel.

\begin{tabular}{|c|c|c|c|c|}
\hline $\begin{array}{l}\text { Specimen } \\
\text { number }\end{array}$ & $\begin{array}{c}\text { Specimen size } \\
(\text { length } \times \text { width } \times \text { height }) \\
\left(\mathrm{mm}^{3}\right)\end{array}$ & $\begin{array}{l}\text { PLC material thickness } \\
\qquad(\mathrm{mm})\end{array}$ & $\begin{array}{l}\text { GRC material thickness } \\
\qquad(\mathrm{mm})\end{array}$ & Interface connection method \\
\hline T0 & $1000 \times 1000 \times 15$ & - & 15 & - \\
\hline $\mathrm{T} 1$ & $1000 \times 1000 \times 60$ & 60 & - & - \\
\hline $\mathrm{T} 2$ & $1000 \times 1000 \times 15$ & - & 15 & - \\
\hline T3 & $1000 \times 1000 \times(60+10)$ & 60 & 10 & Smooth \\
\hline $\mathrm{T} 4$ & $1000 \times 1000 \times(60+15)$ & 60 & 15 & Smooth \\
\hline T5 & $1000 \times 1000 \times(60+15)$ & 60 & 15 & Rough \\
\hline T6 & $1000 \times 1000 \times(60+15)$ & 60 & 15 & Laying steel mesh \\
\hline
\end{tabular}

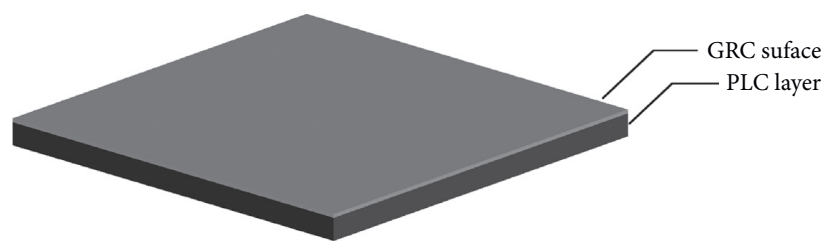

FIGURE 4: GRC-PLC composite panel.

material based on the design mix proportion, a concrete mixer was used for mixing; subsequently, water and the water-reducing agent are added in a sequence every $8 \mathrm{~min}$. After the GRC material was stirred, it was poured on the surface of the lightweight concrete, and the surface was levelled using a roller brush while ensuring a bubble-free surface. Thus, the effects of GRC layer thickness and type of composite method used for the composite interfaces (smooth, rough, and laying steel mesh) on the shrinkage properties of the GRC-PLC composite panels were studied. When pouring T5 and T6 composite panels, the composite interface was processed using rough and laying steel meshes. The strain gauge was placed in the pouring material at the same time. When pouring PLC, the embedded strain gauge was placed inside it. When pouring the GRC, the surface strain gauge was prevented from sinking and contacting the PLC given the softness of the GRC material. It was placed using a wooden stick on the template, and a string was used for fixing. Figure 5 shows the placement of the strain gauges and the experimental process. The two strain gauges were connected to the static strain tester, and the panel surface was covered using a fresh-keeping film. Water was sprayed onto the panel surface for seven days in the morning, midday, and evening. The 

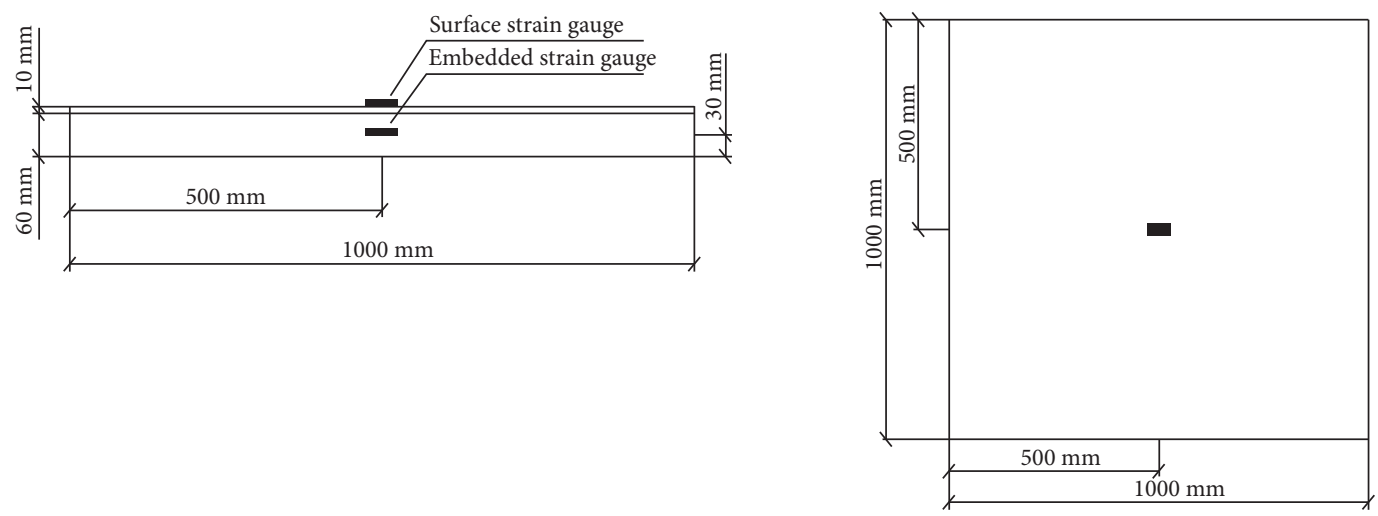

(a)

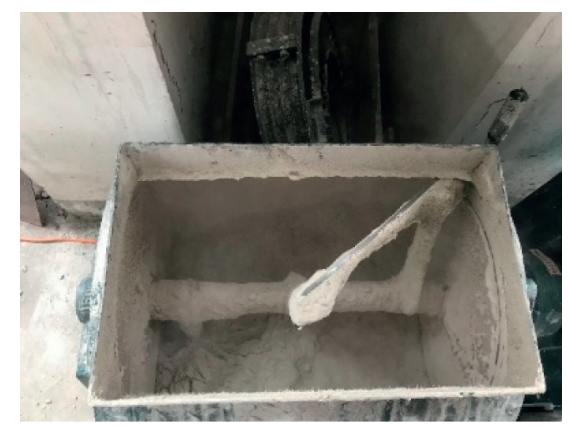

(c)

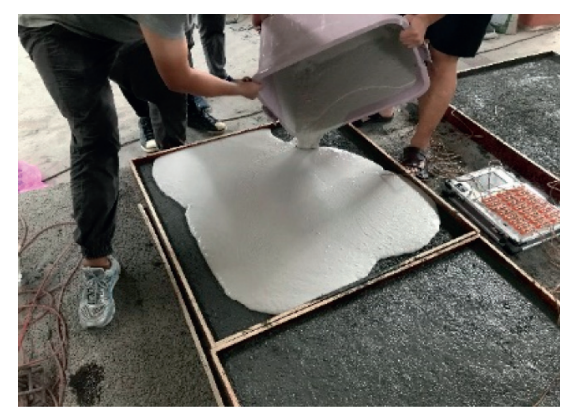

(f)

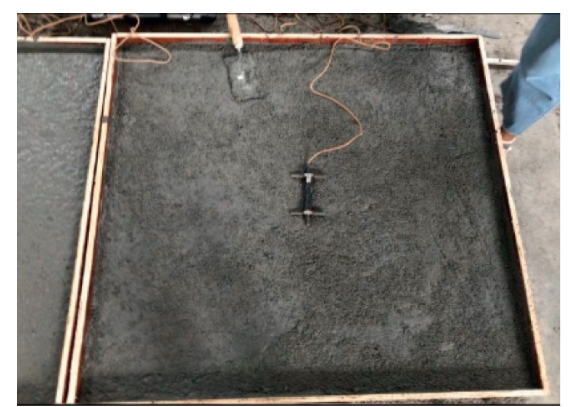

(i)

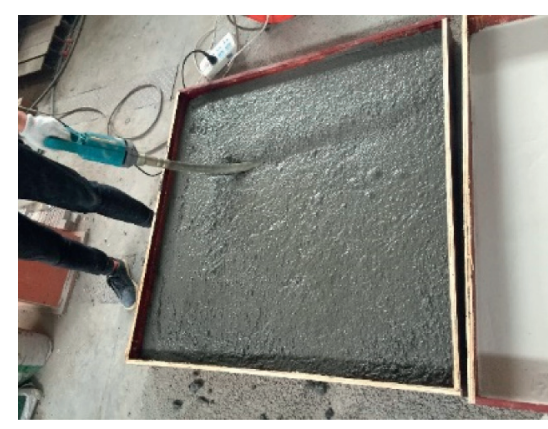

(d)

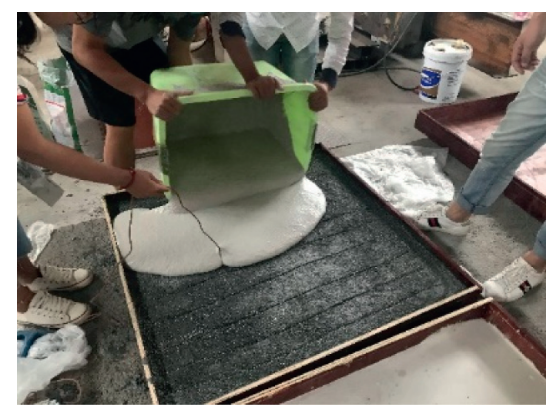

(g)

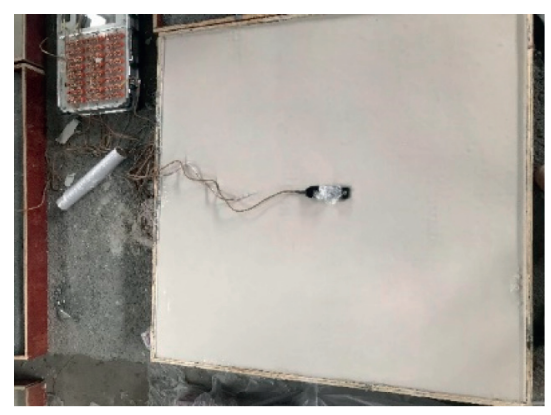

(j) (b)

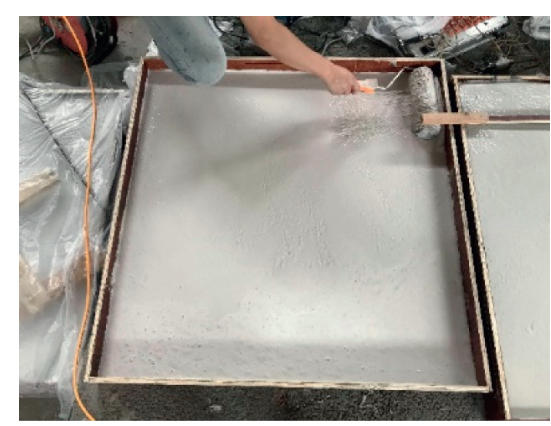

(e)

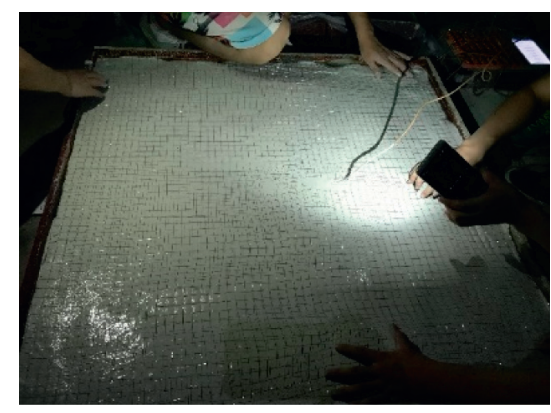

(h)

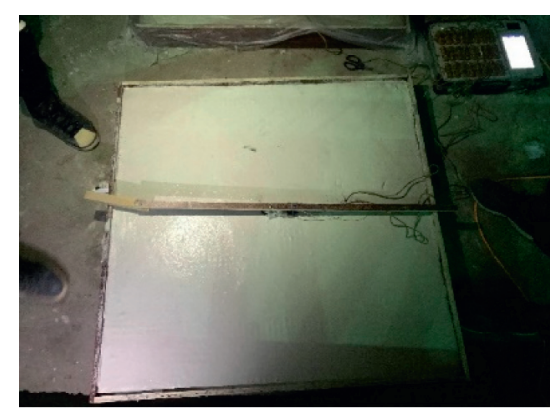

(k)

FIGURE 5: Composite panel production process. (a) Location of surface strain gauge. (b) Location of embedded strain gauge. (c) Mixing GRC. (d) Vibration rod vibration. (e) Roller brushing. (f) Smooth connection. (g) Rough connection. (h) Laying steel mesh connection. (i) Embedded strain gauge. (j) Surface strain gauge. (k) Fixed surface strain gauge. 
shrinkage strain value of the GRC-PLC composite board was continuously monitored, and the temperature and humidity were recorded every morning, midday, and evening.

\section{Results and Discussion}

\subsection{Effect of Material Compositions on Flexural Strength and Drying Shrinkage Properties of GRC}

3.1.1. Effects of Fiber and Rubber Powder Contents on Flexural Strength of GRC. Figure 6 shows the flexural strength histogram of mortars with different fibers and rubber powder contents under a relative humidity of $40 \%$. Figure 6(a) shows that when the fiber contents are $1 \%$, $1.5 \%$, and $2 \%$, the flexural strengths of the mortar cured for 28 days are $11.9,13.5$, and $15.6 \mathrm{MPa}$, respectively. This shows that the flexural strength of the mortar can be improved with the increase in the fiber content. The main reason is that the glass fiber can improve the tensile strength and deformation ability of the mortar, and it can prevent the expansion of the original microcracks in the mortar and delay the generation of new cracks [33]. Based on a $2 \%$ fiber content, after adding $1.5 \%, 2.5 \%$, and $3.5 \%$ rubber powder, the flexural strengths of the mortar on the 28 th day were $16.1,16.7$, and $15.2 \mathrm{MPa}$, respectively, as shown in Figure 6(b). The flexural strength of the mortar can be continuously and effectively improved when the rubber powder content is $<2.5 \%$. The main reason is that the flexural strength of the mortar is improved when adding an appropriate amount of rubber powder. The emulsified rubber powder has the effect of bonding polymerization and helps improve the bonding strength between the cement, aggregate, and fiber. However, when the rubber powder content is $>2.5 \%$, the flexural strength of the mortar begins to decrease. With the increase in the rubber powder content, too many voids are introduced [34], which increases the overall porosity of the mortar and reduces the bonding degree between the fiber and the mortar, thereby reducing the flexural strength of the mortar. Therefore, when the rubber powder content is $<2.5 \%$, the flexural strength can be continuously and effectively improved.

Figure 7 shows the flexural strength of the mortar with different fiber and rubber powder contents under a relative humidity of $70 \%$. As shown in Figure $7(\mathrm{a})$, when the fiber contents are $1 \%, 1.5 \%$, and $2 \%$, the flexural strengths of the mortar cured for 28 days are $12.1,15.8$, and $17.9 \mathrm{MPa}$, respectively. Compared with the mortar cured under a relative humidity of $40 \%$, the flexural strength of the mortar cured for 28 days with different fiber contents is higher. The main reason is that the hydration of cement under $70 \%$ relative humidity is more sufficient, the hydration strength increases, and the bonding force between the fiber and the cement-based material is further enhanced [35]. Figure 7(b) shows that with the incorporation of the rubber powder, the flexural strength of the mortar is consistent with that of the mortar prepared under $40 \%$ relative humidity. When the amount of rubber powder is $>2.5 \%$, the flexural strength of the mortar decreases. With the increase in the amount of rubber powder, the flexural strength increases first but then decreases on the 28th day.
3.1.2. Effects of Fiber, Rubber Powder, and Expansion Agent Contents on Drying Shrinkage Properties of GRC. The experiment of drying shrinkage was based on "Standard test methods for drying shrinkage and cracking possibility of cement mortar and concrete" (GB/T 29417-2012) [36] in this paper. This standard code has explained how to carry out the drying shrinkage experiment. However, the standard code did not specify the limit of drying shrinkage. Therefore, our drying shrinkage experiments were based on this specification.

(1) Effect of Fiber Content on Drying Shrinkage Performance of GRC. Figures 8(a) and 8(b) show the drying shrinkage rate of mortar specimens with different fiber contents prepared under $40 \%$ and $70 \%$ relative humidity, respectively. As shown, an increase in the fiber content from $1 \%$ to $2 \%$ has little effect on the drying shrinkage performance of the mortar. This is because the fiber can reduce the water loss area of the mortar, and the water transfer path is prolonged [37]. Moreover, the disorderly distribution of the fiber blocks the connectivity of the capillary in the mortar and reduces the capillary tension generated by the capillary water loss and contraction. Therefore, it is can reduce the dry shrinkage of the mortar. Therefore, in terms of the drying shrinkage characteristics, the fiber content should be no more than $1 \%$ to effectively inhibit the increase in the drying shrinkage rate. When the relative humidity increases from $40 \%$ to $70 \%$, the shrinkage rate on the 28 th day can be reduced by approximately $40 \%$, which is evidently beneficial for reducing the shrinkage rate of the mortar specimens. Increasing the curing humidity during the curing process can significantly reduce the drying shrinkage of GRC materials.

(2) Effect of Rubber Powder Content on Drying Shrinkage of GRC. Figure 9 shows the shrinkage of mortar specimens with different amounts of rubber powder prepared at $40 \%$ and $70 \%$ relative humidity. The two line graphs show a rapid increase in the shrinkage rate within 0-7 days, indicating that the incorporation of rubber powder led to an increase in the shrinkage rate of the GRC and that the shrinkage rate increases gradually after seven days. Compared with the mortar without rubber powder, the dry shrinkage of the mortar is evidently increased with the increase in the amount of rubber powder. The main reason is that the addition of rubber powder increases the number of microholes in the mortar, thereby increasing the capillary tension and causing shrinkage. The drying shrinkage curves under $70 \% \mathrm{RH}$ and $40 \% \mathrm{RH}$ exhibit the same trend; however, the GRC drying shrinkage under $70 \% \mathrm{RH}$ is relatively low. This shows that the drying shrinkage of the mortar can be effectively inhibited by increasing the curing humidity.

(3) Effect of U-Type Expansion Agent (UEA) Content on Drying Shrinkage Performance of GRC. Figure 10 shows the effect of the expansion agent on the shrinkage performance of the GRC under different humidity environments. As shown, when the humidity is $40 \%$, the drying shrinkage rate of the GRC is significantly higher than that of the GRC 


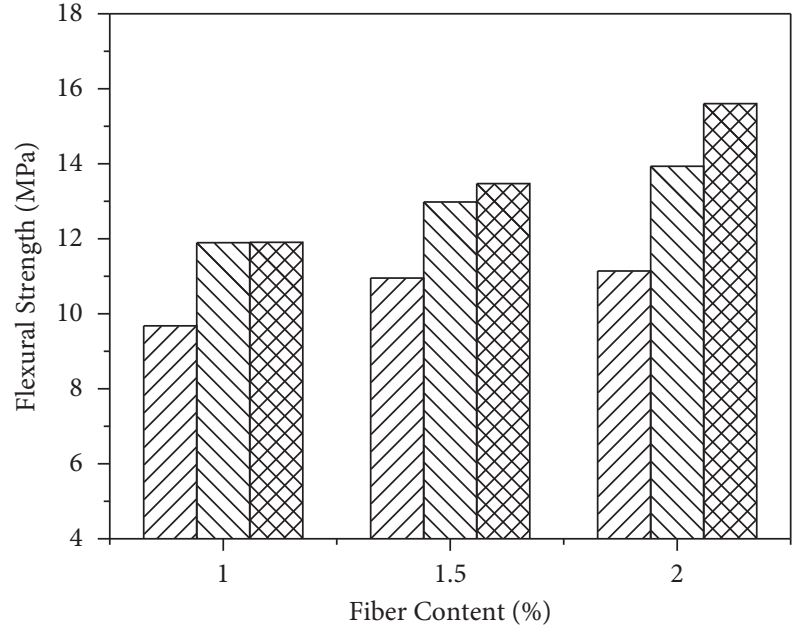

$D^{3}{ }^{3 \mathrm{~d}}$
$M{ }^{7 \mathrm{~d}}$
$28 \mathrm{~d}$

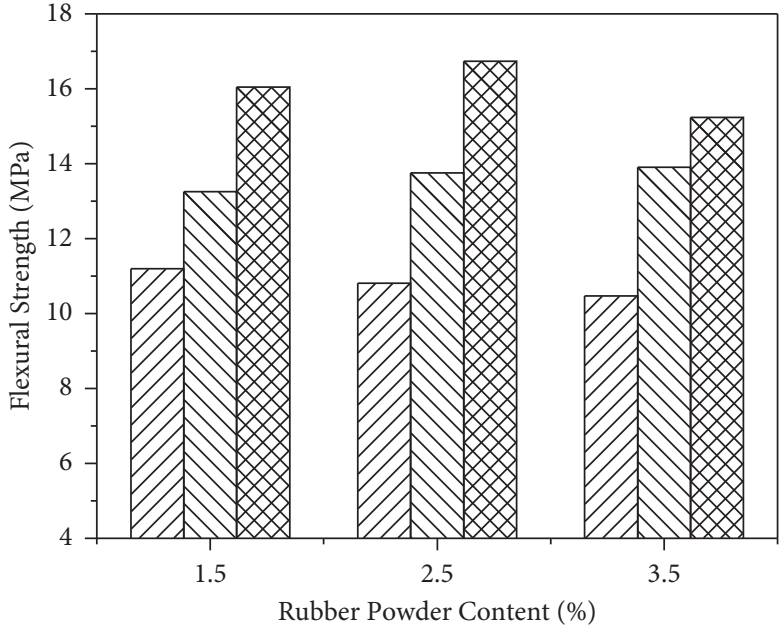

D/7 $3 \mathrm{~d}$
$M 17 \mathrm{~d}$
$28 \mathrm{~d}$

(a)

(b)

FIGURE 6: Flexural strength of mortar with different fiber and rubber powder contents when $\mathrm{RH}=40 \%$. (a) Fiber content. (b) Rubber powder content.
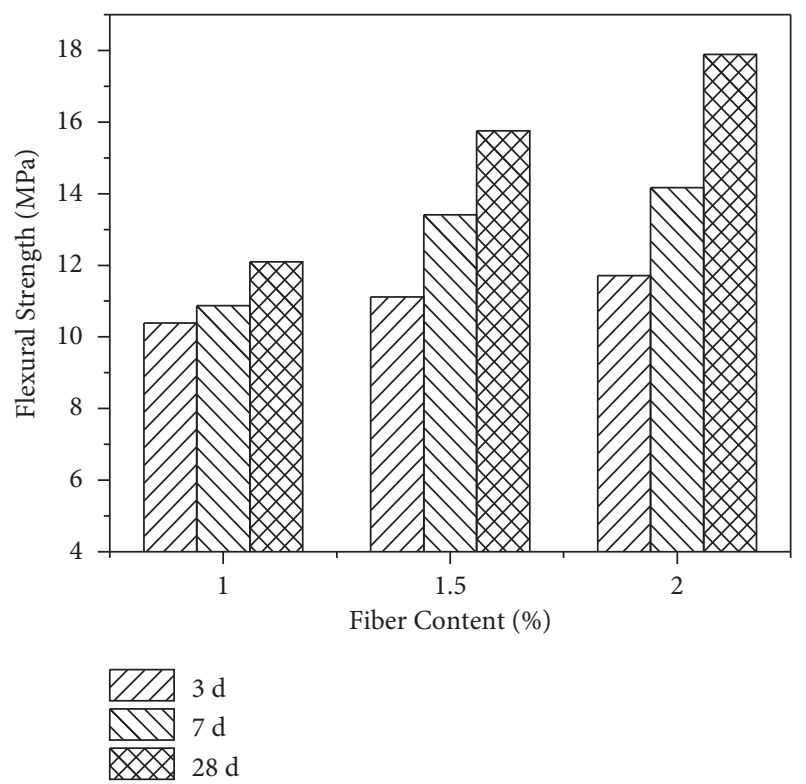
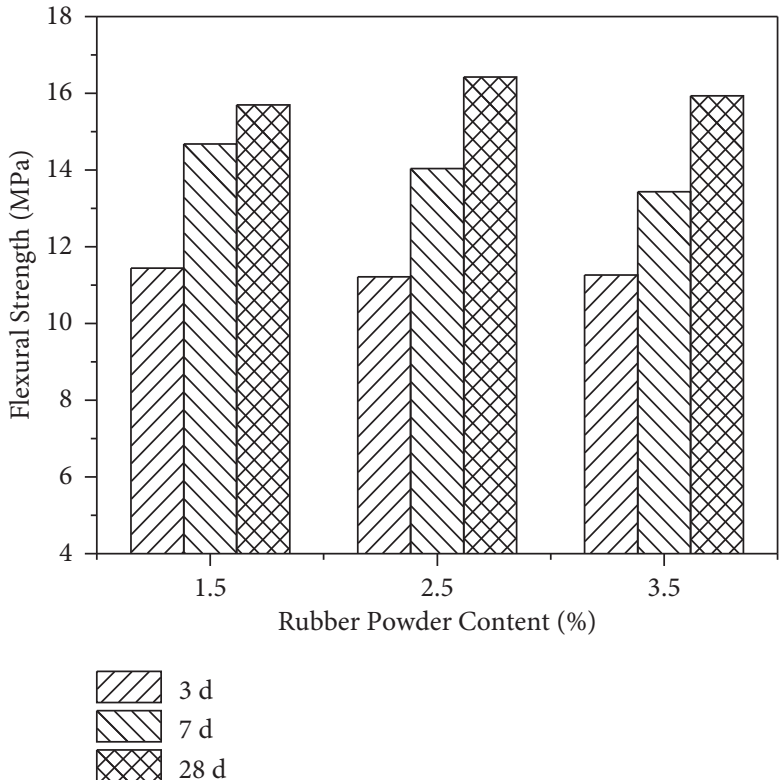

(a)

(b)

FIgURE 7: Flexural strength of mortars with different fiber and rubber powder contents when RH=70\%. (a) Fiber content. (b) Rubber powder content.

prepared at $70 \%$ humidity, indicating that the humidity can improve the drying shrinkage performance of the GRC. At $40 \%$ relative humidity, the drying shrinkage rate of the GRC with the expansion agent is significantly lower than that of the GRC without the expansion agent. After 15 days, the drying shrinkage rate of the GRC with the expansion agent is lower than that of the GRC cured at 70\% humidity. The components have a certain hydration and expansion capacity in the U-type expansion agent. Adding the expansion agent can prevent the early-age shrinkage strain and reduce the risk of early-age cracks [38]. At the same time, the drying shrinkage of the mortar can be inhibited by increasing the curing humidity.

In summary, (1) the incorporation of $3 \mathrm{~mm}$ alkali-resistant glass fibers can help reduce the drying shrinkage of the mortar to a certain extent and significantly increase its 


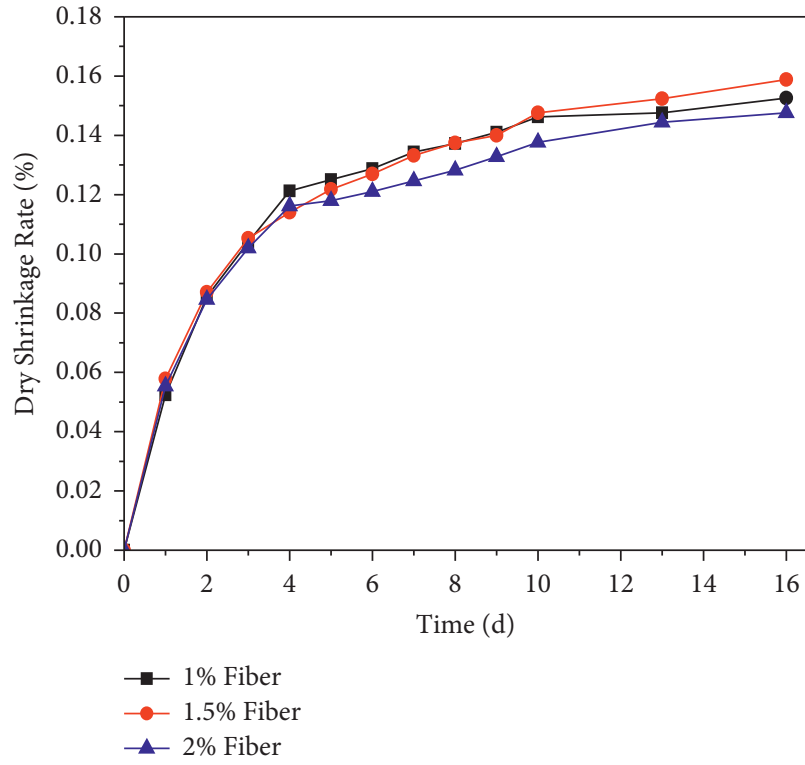

(a)

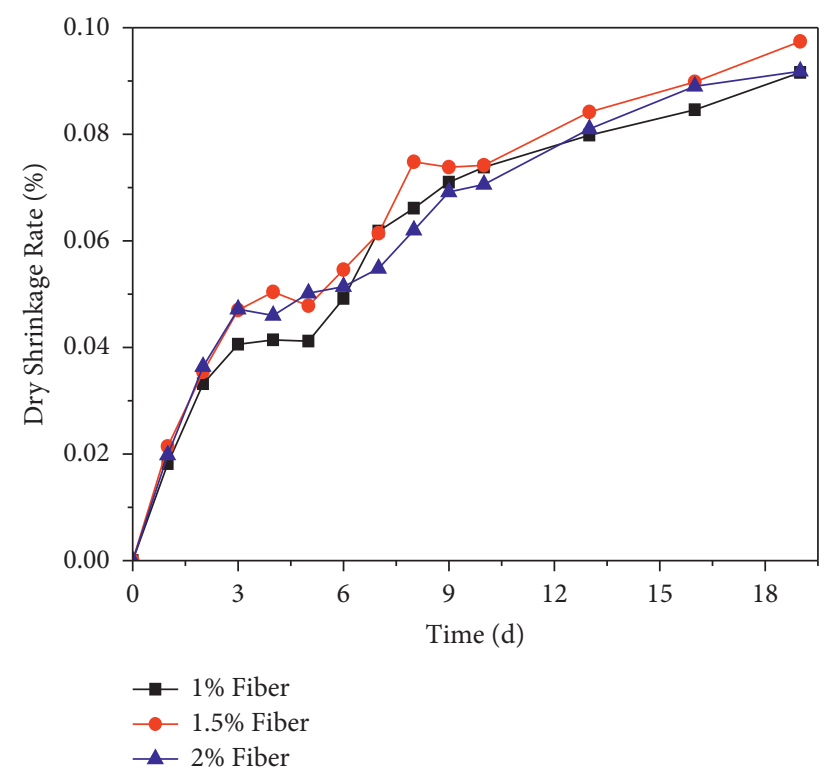

(b)

Figure 8: Drying shrinkage rate of mortar with different fiber contents under (a) $\mathrm{RH}=40 \%$ and (b) $\mathrm{RH}=70 \%$.

flexural strength, thereby improving the crack resistance of the matrix. The greater the amount of fiber, the more evident the effect. (2) In the blending amount range of $0-3.5 \%$ dispersible rubber powder, with the blending of the dispersible rubber powder, the flexural strength of the mortar first increases and then decreases. It can improve its crack resistance. However, the incorporation of the rubber powder will reduce the flexural strength and increase the capillary tension because of the introduction of more pores, which aggravate the drying shrinkage of the mortar. (3) UEA can prevent harmful cracks in the concrete due to shrinkage stress and improve the compactness and impermeability. The results showed that cement mortar with $8 \%$ UEA can exhibit a certain degree of microexpansion performance.

\subsection{Drying Shrinkage Performance of GRC-PLC Composite} Panels. The shrinkage of a GRC-PLC composite panel includes temperature shrinkage, drying shrinkage, plastic shrinkage, carbonization shrinkage, and autogenous shrinkage. Faez Sayahi et al. [39] believe that cement shrinkage and deformation is the main cause of cracking. Therefore, the composite panel cracks can be reflected by monitoring the shrinkage strain of the panel.

T0 was a GRC panel without fiber, which was completed on June 1, 2019. T0 was not composite with other materials, so it can shrinkage freely. However, after three months of $\mathrm{T} 0$, there were cracks in the middle of the plate (Figure 11(a)). This phenomenon shows that the different position of the panel has different shrinkage strain, resulting in different shrinkage stress. At the same time, according to the distribution of cracks in the panel, the middle of the panel was free to shrinkage and deform, resulting in the shrinkage stress exceeded the ultimate tensile strength of GRC materials, and producing cracks finally. Therefore, it was reasonable to place the strain gauge in the middle of the panels (Figure 11(b)). And T1-T6 were not found cracks in the monitoring period, which can indicate that the new GRC-PLC composite panel met the resistance requirements.

The temperature and humidity changes affect the shrinkage of the composite panel, and these changes were recorded during the test monitoring period. Figure 12 shows that in the first three months, the temperature drops from summer to winter, and the temperature in winter stabilizes at approximately $5^{\circ} \mathrm{C}$ for the next two months and then shows a rising trend toward spring and summer. For an entire year, the indoor temperature and humidity were recorded in the morning, noon, and evening, and the average value was used to draw the temperature and humidity curve charts. Due to the change of the actual application environment of the panels, the monitoring time of the panels was set as one year to improve the integrity of the experiment.

3.2.1. Dry Shrinkage Properties of Pure GRC and Pure PLC Specimens. Table 6 lists the maximum shrinkage strains of the six specimens based on monitoring data obtained experimentally.

$\mathrm{T} 1$ and $\mathrm{T} 2$ represent pure PLC and pure GRC specimens, respectively, which can be used as the test basis for comparison. The shrinkage strains of the other specimens can be referred from the analysis of the basis specimen. Figure 13 shows the shrinkage strain curves of the $\mathrm{T} 1$ and $\mathrm{T} 2$ specimens with time. The figure shows that the hydration reaction is intense at the beginning of the test and that the strain of the $\mathrm{Tl}$ specimen gradually increases with time. At this time, the lightweight concrete is stretched because of expansion. Later, as the 


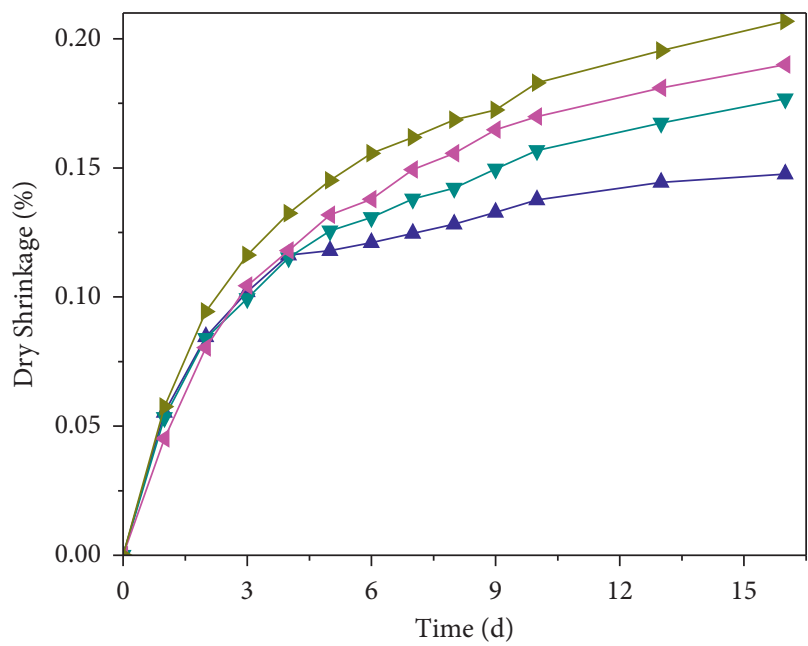

$-0 \%$ Rubber Powder $\rightarrow$ 2.5\% Rubber Powder
$\rightarrow-1.5 \%$ Rubber Powder $\rightarrow 3.5 \%$ Rubber Powder

(a)

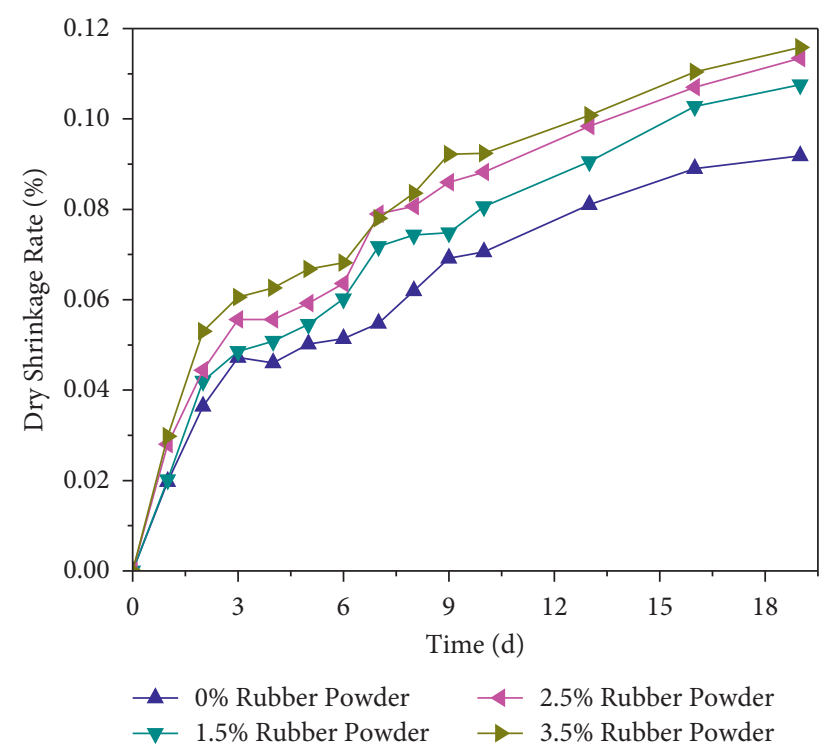

(b)

FIGURE 9: Drying shrinkage rates of mortar with different rubber powder contents under (a) $\mathrm{RH}=40 \%$ and (b) $\mathrm{RH}=70 \%$.

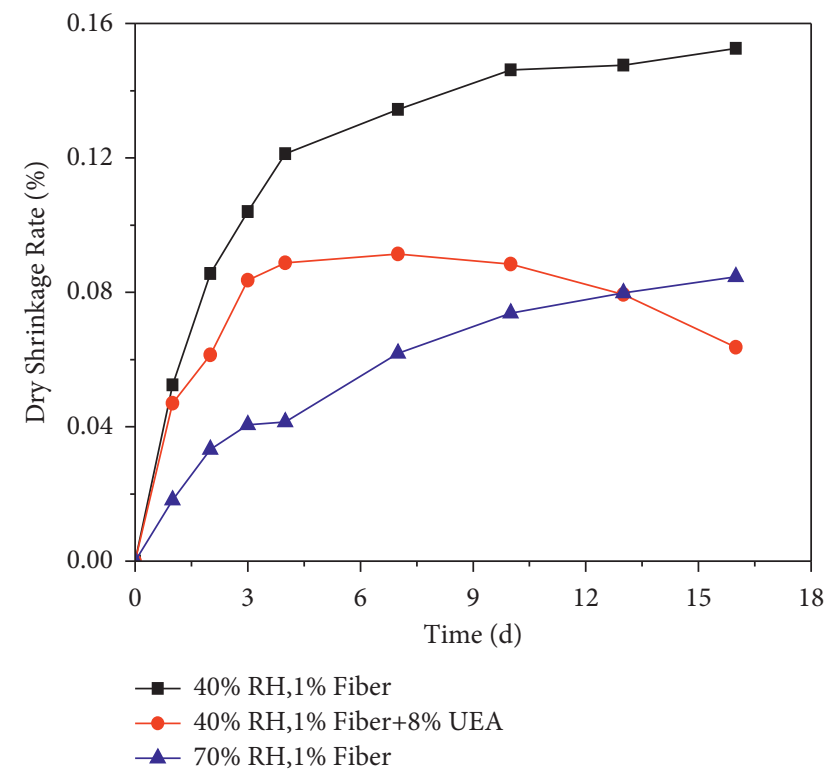

FIGURE 10: Effect of expansion agent content on drying shrinkage performance of GRC prepared under different humidity environments.

hydration reaction gradually weakens and the temperature changes, the strain of the T1 specimen changes from positive to negative, indicating that it is in a state of contraction. In the early stage of the experiment, the hydration reaction of the T2 specimen is intense, which stretched the T2 specimen because of expansion. The strain in the T2 specimen shows a wave-type fluctuation with time because of the influences of temperature and humidity in the later period. Compared with that shown in Figure 12, the drying shrinkage of GRC material is significantly affected by the temperature and humidity, resulting in a fluctuation in the strain of the T2 specimen.
These two panels were used as the basic comparison panel for the experiment. Rafał Stanisław and Barbara [40] believe that the shrinkage of lightweight concrete was not greater than that calculated for normal weight concrete of a similar strength class. At the same time, it can be seen from Figure 13 that PLC and GRC have different shrinkage performances. The shrinkage strain of PLC is smaller than that of GRC. After the composite, there was a strain difference between the two materials. Therefore, the influence of different connection modes of PLC and GRC on shrinkage performance was studied.

3.2.2. Surface and Internal Dry Shrinkage Performance of T3-T6 Composite Panels. Figure 14 shows the variation curves of the surface and internal shrinkage strains with the time of specimens T3-T6. At an early age, hydration of cement leads to a reduction in volume that induces autogenous shrinkage. Because autogenous shrinkage occurs in cement mortar, the performance of thermal expansion was different between cement motor and aggregates. The internal shrinkage stress was incompatible, and it cannot reach the self-equilibrated state of stress [41]. By comparison, the shrinkage strain of these specimens shows an increasing trend over time because of the hydration reaction; the specimens begin to expand in tension, and the strain gradually increases at the beginning of the experiment. Later, as the hydration reaction gradually weakens, the GRC materials and PLC begin to shrink, and the strain on the surface and inside of the specimen changes from positive to negative. In addition, as shown in Figure 14, the shrinkage deformation trend of GRC layer and PLC layer is basically the same, suggesting that the shrinkage deformation between GRC 


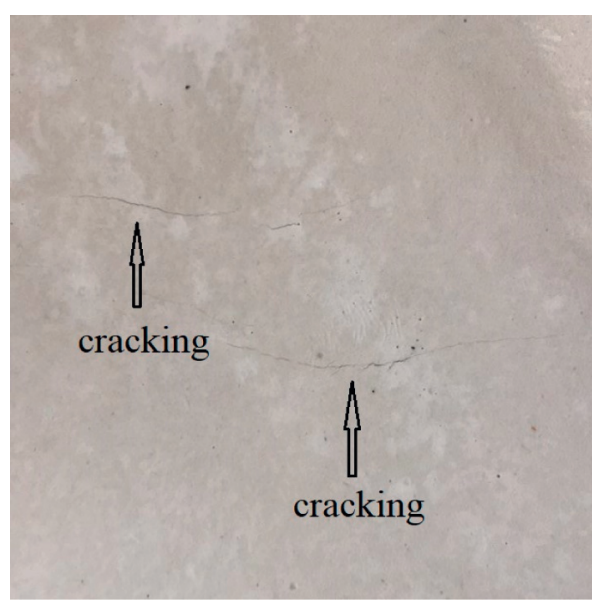

(a)

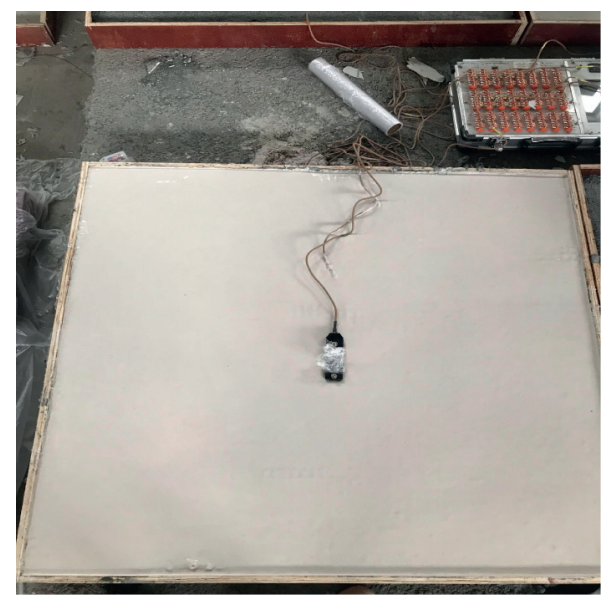

(b)

Figure 11: Difference of panels. (a) T0. (b) T2.

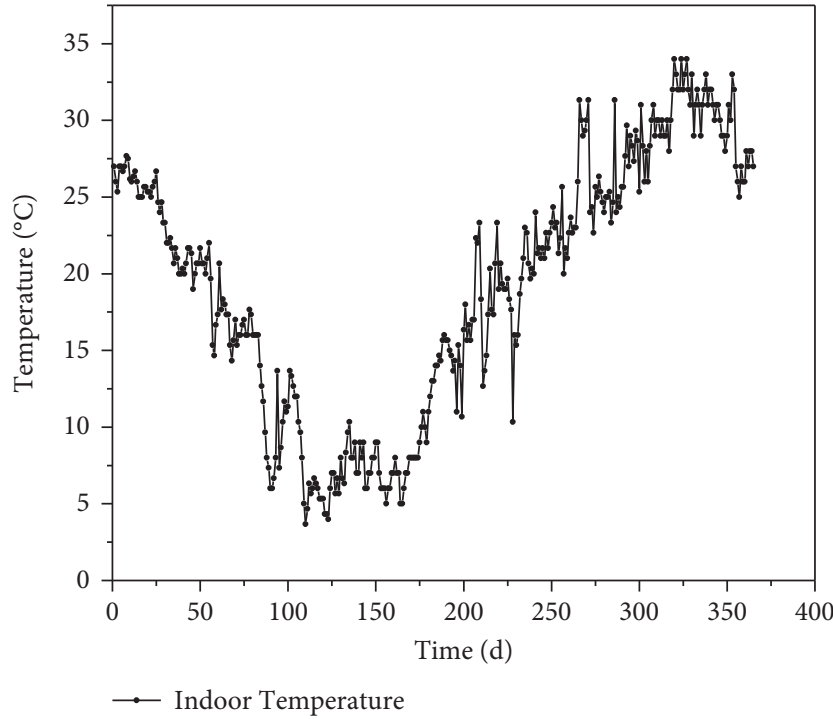

(a)

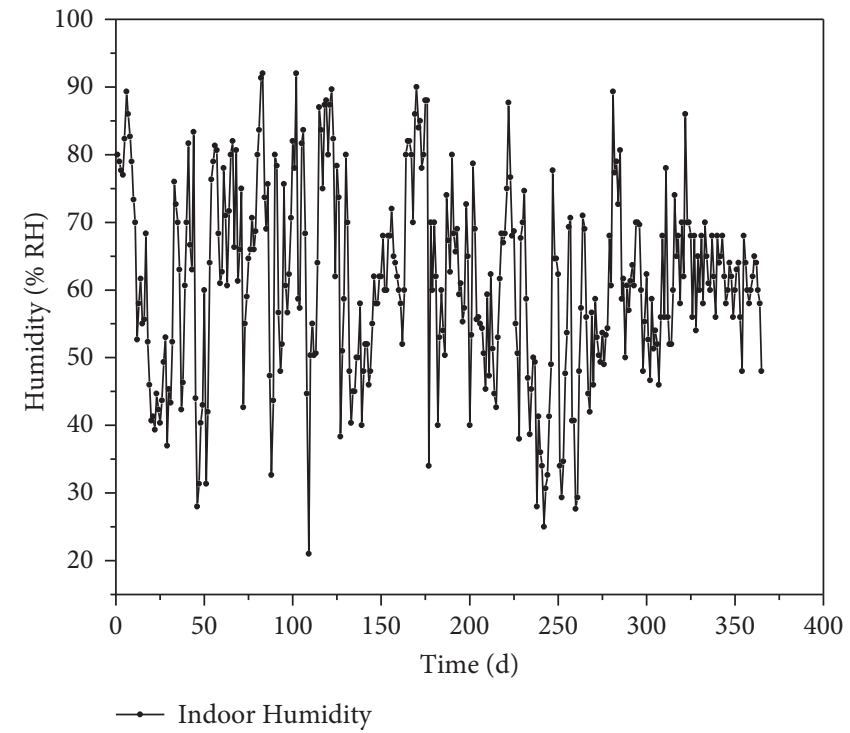

(b)

FIGURE 12: (a) Indoor temperature and (b) indoor humidity change curves with time.

layer and PLC layer is coordinated. Compared with T3 and $\mathrm{T} 5$, the deformation coordination of $\mathrm{T} 4$ and $\mathrm{T} 6$ is better, which is beneficial to the overall crack resistance of GRC-PLC composite panel.

\subsubsection{Influence of GRC Material Thickness on Shrinkage} Performance of Composite Panel. To explore the influence of GRC thickness on the shrinkage performance of the composite panels, GRC specimens with two different thicknesses were designed for the experiment: $10 \mathrm{~mm}$ (T3) and $15 \mathrm{~mm}$ (T4). Torres et al. [42] believe that the amount of cement used affects the aggregate coating thickness, which has an effect on the porosity and other mechanical properties of the concrete. Because the thermal expansion performance of GRC and PLC materials was different. Therefore, GRC thickness will affect the shrinkage performance of composite wall panel.

Figure 15 shows a comparison between the pure GRC material and GRC composite panel of different thicknesses in terms of their surface shrinkage performance. At the beginning of the test, the shrinkage strains of the specimens $\mathrm{T} 2, \mathrm{~T} 3$, and T4 increase because of the hydration reaction. At this time, the specimen is in a state of expansion and tension. Later, the hydration reaction weakens, the specimen is in a compression state, and the shrinkage strain tends to stabilize. The strain value of the T2 specimen shows a wave-like fluctuation after 28 days, and the change trends in the T3 and T4 specimens are different, indicating that the GRC material thickness has a certain degree of influence on the surface shrinkage properties of the composite panels. From the data listed in Table 6, the maximum shrinkage strain of the T3 
TABLE 6: Maximum shrinkage strain values of various specimens.

\begin{tabular}{lcc}
\hline Category & Surface shrinkage strain value (GRC) & Internal shrinkage strain value (PLC) \\
\hline T1 & - & $908.64 \times 10^{-6}$ \\
T2 & $1594.30 \times 10^{-6}$ & - \\
T3 & $703.91 \times 10^{-6}$ & $914.76 \times 10^{-6}$ \\
T4 & $731.48 \times 10^{-6}$ & $897.20 \times 10^{-6}$ \\
T5 & $791.74 \times 10^{-6}$ & $684.33 \times 10^{-6}$ \\
T6 & $780.23 \times 10^{-6}$ & $773.57 \times 10^{-6}$ \\
\hline
\end{tabular}

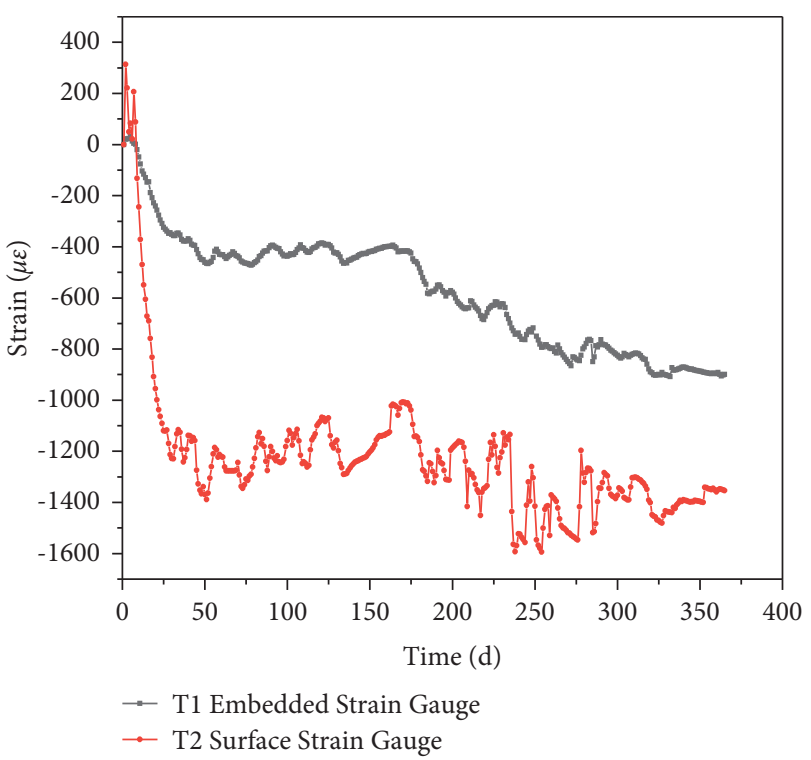

FIgURE 13: Strain curves of $\mathrm{T} 1$ and $\mathrm{T} 2$ specimens with time.

specimen is reduced by $56 \%$ compared with that of the T2 specimen, and the maximum shrinkage strain of the T4 specimen is reduced by $54 \%$ compared with that of the T2 specimen.

Figure 16 shows a comparison diagram of the internal shrinkage performance of pure lightweight concrete materials and GRC composite panels of different thicknesses. At the beginning of the test, because of the hydration reaction, the specimen is in the state of expansion and tension, and the hydration reaction is weakened in the later stage; the specimen is in a state of compression, and the shrinkage strain tends to be stable. The figure shows that the internal shrinkage strains of specimens T1, T3, and T4 exhibit a downward trend in the later stage, and the shrinkage strain of the T4 specimen is lower than those of specimens T1 and T3. From the data listed in Table 6, the maximum shrinkage strain of the T3 specimen is increased by $0.7 \%$ compared with that of the $\mathrm{T} 1$ specimen, and the maximum shrinkage strain of the $\mathrm{T} 4$ specimen is reduced by $1.3 \%$ compared with that of the $\mathrm{T} 1$ specimen.

Compared with simple GRC panel, the shrinkage deformation of the composite GRC layer was obviously small (as shown in Figure 15). This phenomenon shows that the PLC layer obstructs the shrinkage of GRC layer, thus generating tensile stress in the GRC layer. And until the end of the experiment, the tensile stress always existed, but the GRC layer did not crack. This indicates that the shrinkage stress of the GRC layer is less than the tensile strength.
In the early stage of the experiment, the shrinkage deformation of the composite PLC layer was smaller than that of the simple PLC board. However, near the end of the experiment, the deformation is basically the same (Figure 16). This indicates that in the early stage of the experiment, there was a shrinkage stress in the PLC layer, but with the passage of time, the shrinkage stress was gradually reduced. To sum up, after GRC and PLC are compounded, the crack resistance demand of GRC layer is higher.

In addition, the shrinkage deformation curves of GRC layers with different thicknesses are basically the same (as shown in Figure 15). In terms of the production process, the GRC layer of $15 \mathrm{~mm}$ thickness is easier to ensure that the forming quality is that of $10 \mathrm{~mm}$ thickness.

\subsubsection{Influence of Connection Method of Composite Interface} on Shrinkage Performance of Composite Panel. Three types of composite interface connection methods (smooth, rough, and laying steel mesh) were set up in the experiment. By studying the different connection methods of the composite panels, the best connection methods for the two materials were selected. Figure 17 shows the surface shrinkage strain curves with time of the T2, T4, T5, and T6 specimens. The time-strain curves of the T4, T5, and T6 specimens show linear changes in the late experimental period, though the variation ranges of the surface shrinkage strain differ. The surface shrinkage strain of the T5 specimen is lower than those of the T4 and T6 specimens, indicating that the different connection modes of the composite interface have a significant effect on the surface shrinkage performance of the composite panel. From Table 6, it can found that the maximum surface shrinkage strains of the T2, T4, T5, and T6 specimens are $1594.30 \times 10^{-6}, 731.48 \times 10^{-6}$, $791.74 \times 10^{-6}$, and $780.23 \times 10^{-6}$, respectively. The maximum shrinkage strains of the T4, T5, and T6 specimens decrease by more than $50 \%$ compared with that of the T2 specimen. Among them, the surface shrinkage strain of the T5 specimen decreases the most, reaching $62 \%$. Compared with that of $\mathrm{T} 5$, the time-strain curves of T4 and T6 specimens fit the curve of the T1 specimen more closely. Chen et al. [43] studied the effect of different interface connection modes on the drying shrinkage of GRC and concrete composite materials. It can be concluded that different interface connection modes have different effects on GRC drying shrinkage, while smooth connection can effectively inhibit the generation of cracks.

Figure 18 shows the internal shrinkage strain curves of the T1, T4, T5, and T6 specimens with time. Clearly, the four curves exhibit the same trend, and the variation ranges of the 


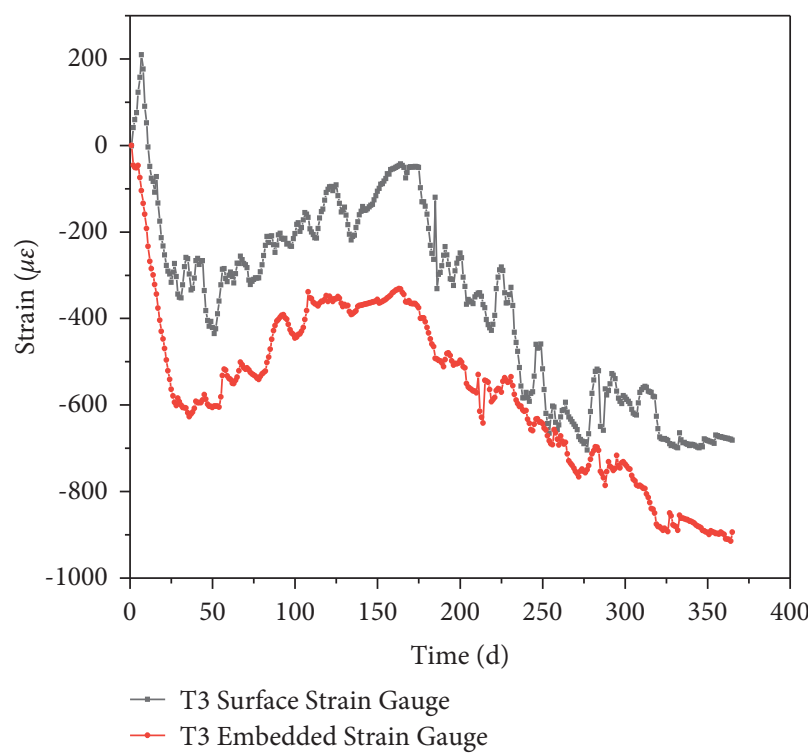

(a)

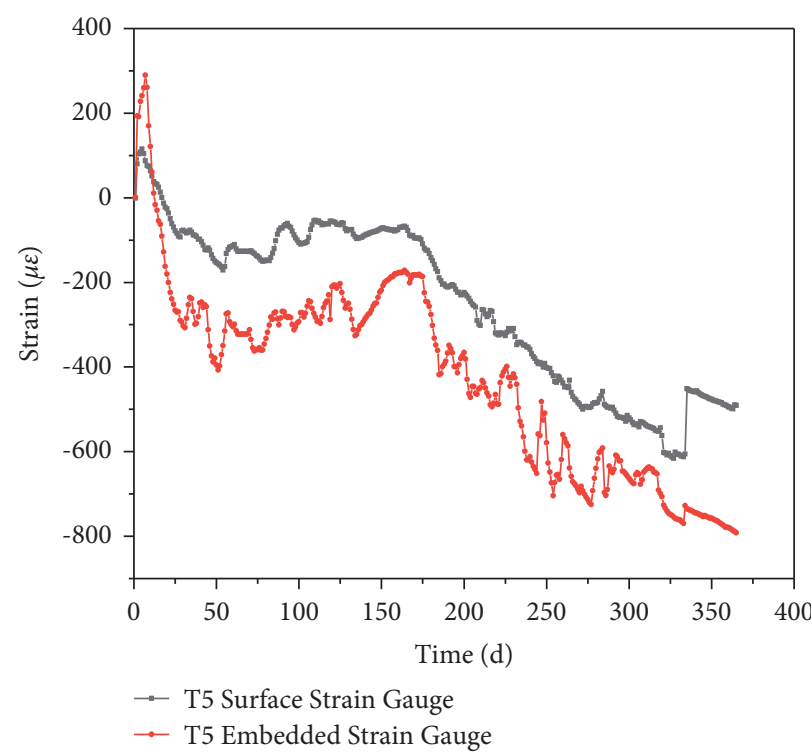

(c)

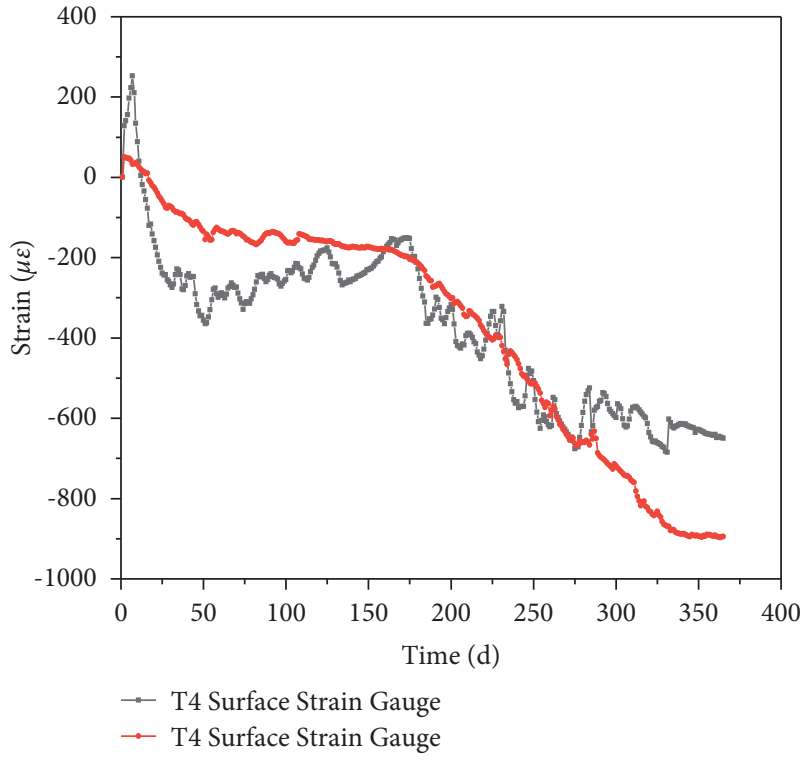

(b)

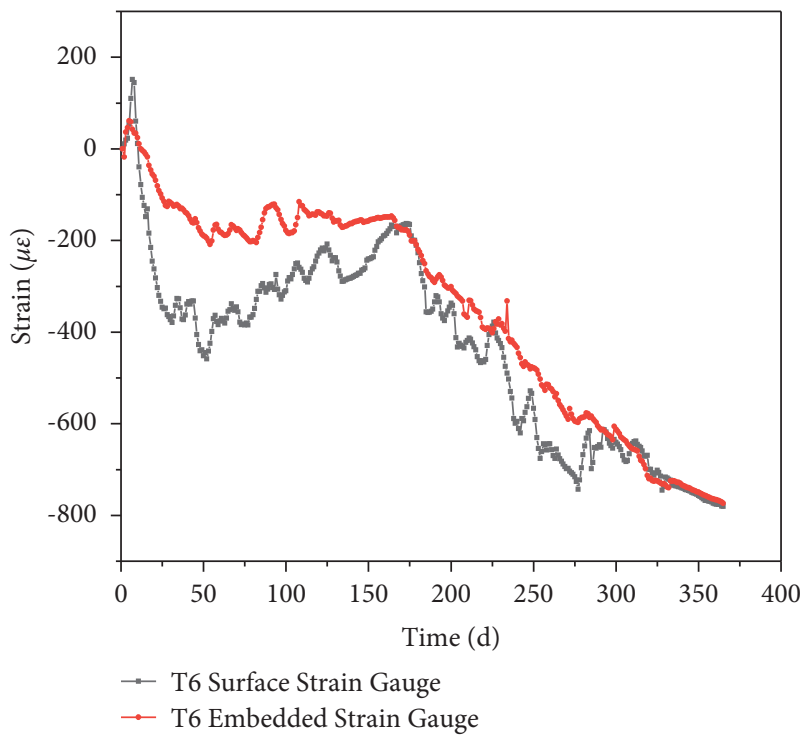

(d)

Figure 14: Curve of specimen shrinkage strain with time. (a) T3 specimen. (b) T4 specimen. (c) T5 specimen. (d) T6 specimen.

time-strain curves of the T4, T5, and T6 specimens are the same. The shrinkage strain values of the T4 and T6 specimens are greater than the strain value of the T5 specimen in the early stage of the experiment. This is mainly attributed to the rough connection affecting the connection between the GRC layer and the lightweight concrete layer. This shows that different connection modes of the composite interface have an impact on the internal shrinkage performance of the composite panel. From Table 6, it can found that the maximum internal shrinkage strains of the T1, T4, T5, and T6 specimens are $908.64 \times 10^{-6}, 897.20 \times 10^{-6}, 684.33 \times 10^{-6}$, and $773.57 \times 10^{-6}$, respectively. The graph shows that the maximum internal shrinkage strains of the T4, T5, and T6 specimens are lower than that of the T1 specimen. Among the three curves, the time-strain curve of the $\mathrm{T} 4$ specimen fits the curve of the T1 specimen more closely.

Compared with simple GRC panel, the shrinkage deformation of the composite GRC layer was obviously 


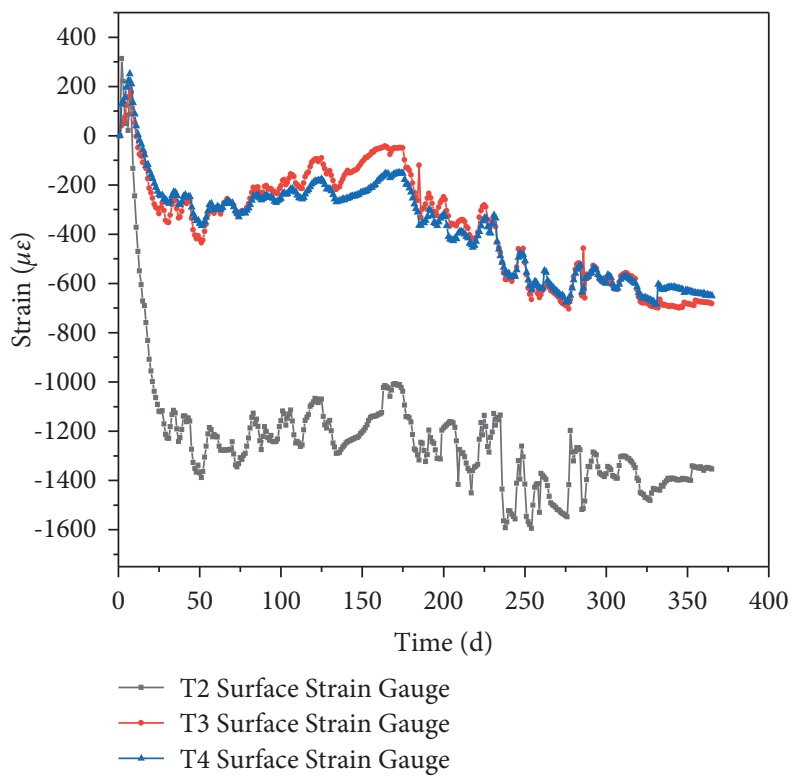

FIgure 15: Surface shrinkage strain curves of T2, T3, and T4 specimens with time.

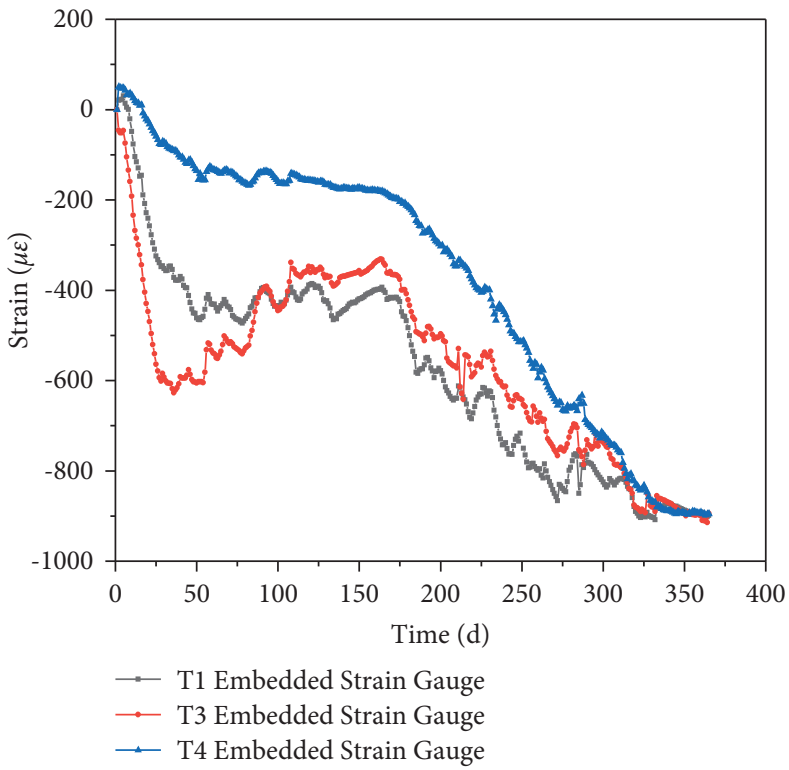

Figure 16: Internal shrinkage strain curves of T1, T3, and T4 specimens with time.

small, as shown in Figure 17. The shrinkage deformation of smooth connection was almost the same as that of steel mesh connection and was larger than that of rough connection. This implies that the shrinkage stress in the composite GRC layer was smaller when the smooth connection and the steel mesh connection are used compared with the rough connection. Near the end of the experiment, the shrinkage deformation of smooth connection is closer to that of T1 panel, which suggests that compared with rough connection and steel mesh connection, the shrinkage stress in PLC layer is smaller when smooth connection was used. As far as the production process is concerned, the use of smooth connection is more efficient than the use of steel mesh connection. Therefore, the use of smooth connection is more reasonable. 


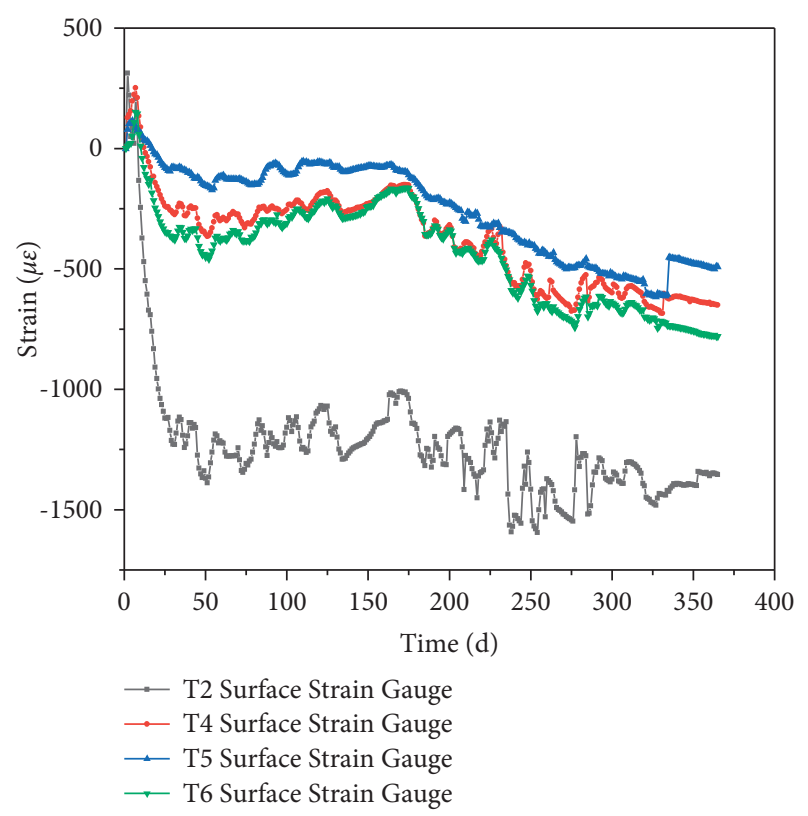

FIGURE 17: Surface shrinkage strain curves of T2, T4, T5, and T6 specimens with time.

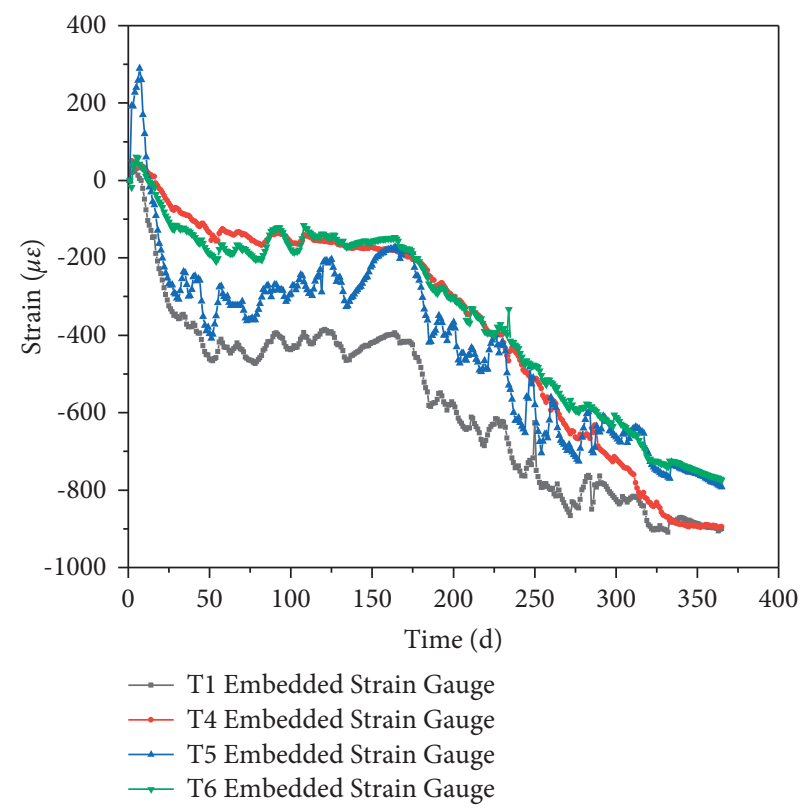

Figure 18: Internal shrinkage strain curves of T1, T4, T5, and T6 specimens with time.

\section{Conclusions}

This research investigated the crack resistance of the GRC-PLC-integrated composite panels, through reducing material shrinkage, improving the tensile strength of cement-based materials, and determining the most effective connection method. During the experiment of about one year, the composite GRC layer did not crack, and thehe following conclusions can be drawn:
(1) According to the monitoring results of T0 panel, the cracks were usually produced in the middle of the panel, where the shrinkage stress was the greatest. Therefore, cracks tend to occur in the middle of the panel.

(2) In GRC material formula, fiber, rubber powder, and expansion agent are the three main components to prevent GRC material cracking. Through the experiment of bending and shrinkage, the better anticrack formula of GRC was obtained.

(3) The shrinkage deformation of the composite GRC layer is not sensitive to the change in thickness, but it is sensitive to the connection mode of the PLC layer. In terms of crack resistance and production process, $15 \mathrm{~mm}$ thickness of GRC layer and smooth connection with PLC layer are more conducive to the application of GRC-PLC composite panel.

GRC-PLC-integrated composite panel is a new type of prefabricated wall that can greatly reduce pollution, shortens the construction period, and improves the construction efficiency. The researches in this paper provide an experimental basis for the large-scale application of the panel.

\section{Data Availability}

All data generated or used during the study are available within the article.

\section{Conflicts of Interest}

The authors declare no conflicts of interest.

\section{Acknowledgments}

This work was supported by Natural Science Foundation of Anhui Province (19080885ME173), Research \& Development project of China State Construction International Holdings Limited (CSCI-2020-Z-06-04), and Science and Technology Project of Anhui Province Housing and UrbanRural Construction (2020-YF47). The authors would like to thank for their financial support.

\section{References}

[1] H. M. Liu, C. Q. Wu, Y. B. Xu, and A. D. Zhu, "Research progress of composite thermal insulation wall in hot summer and cold winter zone of China," Advanced Materials Research, vol. 919-921, pp. 1725-1729, 2014.

[2] B. Cheng, J. Li, V. W. Y. Tam, M. Yang, and D. Chen, "A BIMLCA approach for estimating the greenhouse gas emissions of large-scale public buildings: a case study," Sustainability, vol. 12 , no. 2 , p. $685,2020$.

[3] Iso 22966: 2009, Execution of concrete Structures, International Standard Organization, Beijing, China, 2009.

[4] E. Antoine, T. W. Naaman and G. Hauser, "Influence of different fibers on plastic shrinkage cracking of concrete," ACI Materials Journal, vol. 102, no. 1, pp. 49-58, 2005.

[5] F. Pelisser, A. B. d. S. S. Neto, H. L. L. Rovere, and R. C. d. A. Pinto, "Effect of the addition of synthetic fibers to concrete thin slabs on plastic shrinkage cracking," 
Construction and Building Materials, vol. 24, no. 11, pp. 2171-2176, 2010.

[6] P. S. Song, S. Hwang, and B. C. Sheu, "Strength properties of nylon- and polypropylene-fiber-reinforced concretes," $\mathrm{Ce}$ ment and Concrete Research, vol. 35, no. 8, pp. 1546-1550, 2005.

[7] S. Kakooei, H. M. Akil, M. Jamshidi, and J. Rouhi, "The effects of polypropylene fibers on the properties of reinforced concrete structures," Construction and Building Materials, vol. 27, no. 1, pp. 73-77, 2012.

[8] A. S. El-Dieb and M. M. Reda Taha, "Flow characteristics and acceptance criteria of fiber-reinforced self-compacted concrete (FR-SCC)," Construction and Building Materials, vol. 27, no. 1, pp. 585-596, 2012.

[9] Q. H. Li, J. J. Zhao, Q. Y. Li, J. W. Gao, and Y. J. Wu, "Influence of different dimensions of glass fiber on GRC flexural performance," Journal of Building Materials, vol. 24, no. 3, pp. 1-10, 2020.

[10] C. Cheng, J. He, J. Zhang, and Y. Yang, "Study on the timedependent mechanical properties of glass fiber reinforced cement (GRC) with fly ash or slag," Construction and Building Materials, vol. 217, pp. 128-136, 2019.

[11] J. Payá, M. Bonilla, M. V. Borrachero, J. Monzó, E. PerisMora, and L. F. Lalinde, "Reusing fly ash in glass fibre reinforced cement: a new generation of high-quality GRC composites," Waste Management, vol. 27, no. 10, pp. 1416-1421, 2007.

[12] Y. M. Wang, Y. Z. Tang, and K. W. Liu, "Effect of fiber and rubber powder on mechanics and crack resistance of cement mortar," Bulletin of the Chinese Ceramic Society, vol. 37, no. 9, pp. 2275-2781, 2018.

[13] V. S. Gopalaratnam and R. Gettu, "On the characterization of flexural toughness in fiber reinforced concretes," Cement and Concrete Composites, vol. 17, no. 3, pp. 239-254, 1995.

[14] A. Enfedaque, D. Cendón, F. Gálvez, and V. Sánchez-Gálvez, "Analysis of glass fiber reinforced cement (GRC) fracture surfaces," Construction and Building Materials, vol. 24, no. 7, pp. 1302-1308, 2010.

[15] A. Enfedaque, J. C. Gálvez, and F. Suárez, "Analysis of fracture tests of glass fibre reinforced cement (GRC) using digital image correlation," Construction and Building Materials, vol. 75, pp. 472-487, 2015.

[16] P. R. d. Matos, M. Foiato, and L. R. Prudêncio, "Ecological, fresh state and long-term mechanical properties of highvolume fly ash high-performance self-compacting concrete," Construction and Building Materials, vol. 203, pp. 282-293, 2019.

[17] F. A. Mirza and P. Soroushian, "Effects of alkali-resistant glass fiber reinforcement on crack and temperature resistance of lightweight concrete," Cement and Concrete Composites, vol. 24, no. 2, pp. 223-227, 2002.

[18] M. M. Reda Taha, A. S. El-Dieb, M. A. Abd El-Wahab, and M. E. Abdel-Hameed, "Mechanical, fracture, and microstructural investigations of rubber concrete," Journal of Materials in Civil Engineering, vol. 20, no. 10, pp. 640-649, 2008.

[19] Z. T. Wu, Y. S. Zhang, and N. D. Liu, "Study on shrinkage property of glass fiber reinforced cement base material," Bulletin of the Chinese Ceramic Society, vol. 38, no. 8, pp. 2570-2577, 2019.

[20] P. Van Itterbeeck, P. Purnell, H. Cuypers, T. Tysmans, J. Orlowsky, and J. Wastiels, "Durability models for GRC: uncertainties on strength predictions," Plastics, Rubber and Composites, vol. 41, no. 2, pp. 77-87, 2012.
[21] P. V. Itterbeeck, P. Purnell, H. Cuypers, and J. Wastiels, "Study of strength durability models for GRC: theoretical overview," Composites Part A: Applied Science and Manufacturing, vol. 40, no. 12, pp. 2020-2030, 2009.

[22] J. N. Eiras, T. Kundu, M. Bonilla, and J. Payá, "Nondestructive monitoring of ageing of alkali resistant glass fiber reinforced cement (GRC)," Journal of Nondestructive Evaluation, vol. 32, no. 3, pp. 300-314, 2013.

[23] P. Purnell and J. Beddows, "Durability and simulated ageing of new matrix glass fibre reinforced concrete," Cement and Concrete Composites, vol. 27, no. 9-10, pp. 875-884, 2005.

[24] J. R. Correia, J. Ferreira, and F. A. Branco, "A rehabilitation study of sandwich GRC facade panels," Construction and Building Materials, vol. 20, no. 8, pp. 554-561, 2006.

[25] D. D. Theodorakopoulos, "Shrinkage behaviour of GRC thin sheets," Cement and Concrete Composites, vol. 17, no. 3, pp. 229-238, 1995.

[26] C. M. Cheng, S. L. Hong, Y. F. Zhang, and J. He, "Effect of expanded polystyrene on the flexural behavior of lightweight glass fiber reinforced cement," Construction and Building Materials, vol. 265, Article ID 120328, 2020.

[27] G. W. Leong, K. H. Mo, Z. P. Loh, and Z. Ibrahim, "Mechanical properties and drying shrinkage of lightweight cementitious composite incorporating perlite microspheres and polypropylene fibers," Construction and Building Materials, vol. 246, Article ID 118410, 2020.

[28] R. Chylík, J. Fládr, P. Bílý, T. Trtík, and L. Vráblík, “An analysis of the applicability of existing shrinkage prediction models to concretes containing steel fibres or crumb rubber," Journal of Building Engineering, vol. 24, Article ID 100729, 2019.

[29] J. Ji, H. X. Wang, Q. Wang, Z. Suo, and Z. K. Yuan, "Effect of modified waste rubber powder on properties of cement mortar," Journal of Building Materials, pp. 1-17, 2020.

[30] B. Chen, J. T. Ding, Y. B. Cai, Y. Bai, and W. X. Zhang, "Effect of internal curing and expansive agent on comprehensive crack resistance of concrete," Bulletin of the Chinese Ceramic Society, vol. 44, no. 2, pp. 189-195, 2016.

[31] J. J. Guo, S. W. Zhang, T. Guo, and P. Zhang, "Effects of UEA and $\mathrm{MgO}$ expansive agents on fracture properties of concrete," Construction and Building Materials, vol. 263, no. 2, Article ID 120245, 2020.

[32] Iso 679: 2009, Cement-Test Methods-Determination of Strength, International Standard Organization, Beijing, China, 2009.

[33] A. Ei-Kariem and S. Shoeib, "Efficiency of discrete glass fiber reinforced cement mortar in compression," Advanced Materials Research, vol. 255-260, pp. 3137-3141, 2011.

[34] L. G. Yu, Q. J. Yu, and F. Liu, "Research progress on application of waste rubber powder in mortar concrete," Bulletin of the Chinese Ceramic Society, vol. 26, no. 6, pp. 1148-1152, 2007.

[35] R. V. Ralegaonkar, P. B. Aswath, and A. Abolmaali, "Design investigations of basalt-fibre-reinforced mortar," Proceedings of the Institution of Civil Engineers-Construction Materials, vol. 172, no. 6, pp. 296-304, 2019.

[36] Gb/T 29417-2012, Standard Test Methods for Drying Shrinkage and Cracking Possibility of Cement Mortar and concrete, National Institute of Standards of the People's Republic of China, Beijing, China, 2012.

[37] L. H. Zhang, J. Z. Liu, Z. Q. Yang, D. G. Xu, and L. Li, "Influence and mechanism of PP fiber with different cross section shape on plastic cracking resistance of mortar," 
Journal of Southeast University (Natural Science Edition), vol. 46, no. 1, pp. 160-164, 2016.

[38] P. X. Wang, "Effect of the expansion agent on early-age autogenous shrinkage stress of concrete," Advanced Materials Research, vol. 838-841, pp. 564-568, 2013.

[39] F. Sayahi, M. Emborg, H. Hedlund, and A. Cwirzen, "Plastic shrinkage cracking of self-compacting concrete: influence of capillary pressure and dormant period," Nordic Concrete Research, vol. 60, no. 1, pp. 67-88, 2019.

[40] S. Rafał Stanisław and Ł. Barbara, "Experimental evaluation of shrinkage, creep and prestress losses in lightweight Aggregate concrete with sintered fly ash," Materials, vol. 14, no. 14, p. $3895,2021$.

[41] M. Briffaut, F. Benboudjema, C. Laborderie, and J.-M. Torrenti, "Creep consideration effect on meso-scale modeling of concrete hydration process and consequences on the mechanical behavior," Journal of Engineering Mechanics, vol. 139, no. 12, pp. 1808-1817, 2013.

[42] A. Torres, J. Hu, and A. Ramos, "The effect of the cementitious paste thickness on the performance of pervious concrete," Construction and Building Materials, vol. 95, pp. 850-859, 2015.

[43] D. Chen, P. K. Li, B. Q. Cheng, H. Chen, Q. Wang, and B. Zhao, "Crack resistance of insulated GRC-PC integrated composite wall panels under different environments: an experimental study," Crystals, vol. 11, no. 7, 2021. 